Article

\title{
Mobile Money Use and Healthcare Utilization: Evidence from Rural Uganda
}

\author{
Hiroyuki Egami ${ }^{1, *(1)}$ and Tomoya Matsumoto ${ }^{2}$ \\ 1 Graduate School of Policy Studies, National Graduate Institute for Policy Studies, Tokyo 106-0032, Japan \\ 2 Department of Economics, Faculty of Commerce, Otaru University of Commerce, Hokkaido 047-8501, Japan; \\ tmatsumoto@res.otaru-uc.ac.jp \\ * Correspondence: phd15410@grips.ac.jp
}

Received: 24 March 2020; Accepted: 1 May 2020; Published: 5 May 2020

\begin{abstract}
Lack of cash on hand is a significant obstacle in accessing healthcare services in developing countries. Many expectant mothers in the least developed countries do not receive sufficient care during pregnancy due to financial constraints. If such hurdles in accessing healthcare can be overcome, it will contribute to reduction in maternal and newborn mortality, which is a key target of Sustainable Development Goal 3. This study reports the first assessment of the impact of mobile money services on maternal care utilization. We hypothesize that mobile money adoption would motivate rural Ugandan women to receive antenatal care and to deliver their children at health facilities or with skilled birth attendants. By receiving remittances utilizing mobile money, poor rural households may obtain more cash in hand, which might change women's health-seeking behavior. We apply community- and mother-fixed effects models with heterogeneity analysis to longitudinal panel data (the RePEAT [Research on Poverty, Environment, and Agricultural Technology] survey) of three waves (2009, 2012, and 2015). The analysis uses pregnancy reports of 2007-2015 from 586 rural Ugandan households. We find suggestive evidence that mobile money adoption positively affects the take-up of antenatal care. Heterogeneity analysis indicates that mobile money brings a larger benefit to geographically challenged households by easing their liquidity constraint as they face higher cost of traveling to distant health facilities. The models failed to reject the null hypothesis of no mobile money effect on the delivery-related outcome variables. This study suggests that promoting financial inclusion by means of mobile money motivates women in rural and remote areas to make antenatal care visits while the evidence of such effect is not found for take-up of facility delivery or delivery with skilled birth attendants.
\end{abstract}

Keywords: financial inclusion; mobile money; maternal care; healthcare utilization

\section{Introduction}

In developing countries, a large proportion of the population lacks access to basic financial services because the financial infrastructure is not well developed. Ensuring the ease of access, availability, and usage of financial services such as transfer of money is called "financial inclusion," and the importance of promoting financial inclusion is widely recognized by those involved in addressing poverty [1]. Gaining access to essential financial services will allow the poor to improve their lives through having savings, making investments, and receiving remittances.

As an innovative person-to-person payment technology, mobile money is helping to rapidly expand access to financial services to the poor, thereby promoting financial inclusion in sub-Saharan Africa. Mobile money enables users to send text messages to transfer value (remittance) through mobile phones and reduces the cost of sending money across long distances. A growing body of literature investigates the impact of mobile money on households and examines whether households become 
more successful in smoothing consumption in the face of shocks [2,3], increasing consumption [4-6] or savings [5,7]. The effect of mobile money on increasing consumption was first shown by Munyegera and Matsumoto [4], who used a difference-in-difference approach on a nonexperimental panel data; such a positive effect is also shown by Apiors and Suzuki [5], who used the propensity-score matching approach; and using randomized controlled trial, Lee et al. [6] confirmed the positive effect of mobile money on improving households' welfare such as consumption and savings. Mobile money adoption may have these beneficial effects on households' welfare through enhancing money transfers via informal networks, such as remittances sent by relatives or friends.

Mobile money would allow households to also improve their welfare in the long-term by investing in human capital development, such as education or healthcare. Tabetando [8] found positive mobile money effects on educational investment and the likelihood of school enrollment of children. However, whether mobile money services positively affect health, which is another important factor in human capital, has not been investigated much. Mobile money has the potential to positively affect health-seeking behavior by alleviating the financial resource constraint of households. High out-of-pocket healthcare costs, transportation costs, and opportunity costs are significant barriers to accessing health services in developing countries. The existing literature on financial inclusion has focused its attention on the effect of financial inclusion tools, such as microfinance, on health-seeking behavior [9]. Existing studies for the most part show that supporting poor households to overcome liquidity constraints and to initiate savings had been effective in encouraging them to seek healthcare $[10,11]$. Thus, one can think that mobile money, which is another tool of financial inclusion, may positively influence healthcare utilization.

Among health issues, maternal-child care has been a pressing issue in developing countries. Antenatal care (ANC) is essential in preventing both maternal and infant mortality. The adult lifetime risk of maternal mortality in women from sub-Saharan Africa is the highest in the world. Poorer women face higher barriers to accessing maternity care; the financial barrier has been found to be a key obstacle $[12,13]$. By using cash, vouchers, or goods as demand-side financing tools, the existing literature has studied how effectively those can encourage potential patients to seek maternal healthcare [14-16].

Uganda is among the worst ten countries that comprised $58 \%$ of the global maternal deaths reported in 2013. The maternal mortality ratio (maternal deaths per 100,000 live births) in Uganda is 360 and 22 times higher than that in developed regions (16). It is even higher than the average of developing regions (260) [17]. A well-designed and well-implemented ANC program facilitates the detection and treatment of health problems such as anemia or infection during pregnancy; it also provides an opportunity to disseminate health messages to women and their families. ANC from a trained provider at a high-quality healthcare facility is vital in monitoring the pregnancy and in reducing the morbidity risk for the mother and child during pregnancy and delivery [18].

In addition to ANC, the benefit of delivering with a skilled birth attendant (SBA) or at a healthcare facility versus home birth has been clearly described in the literature [19]. For example, proper medical attention and hygienic conditions during delivery can reduce the risk of infections and complications that may cause death or serious illness to either the mother or the baby (or both) [20]. As Manang and Yamauchi [21] studied about Uganda, an increase in health facilities surrounding mothers' residential areas (supply-side change) can improve the health-seeking behavior of mothers. Evaluation studies find that maternal health service utilization is positively affected by financial inclusion, such as access to microfinance or bank accounts [22,23]. The existing literature, however, has little to say about the impact of mobile money adoption on maternal healthcare.

In this paper, utilizing the RePEAT (Research on Poverty, Environment, and Agricultural Technology) data of Uganda, we attempt to fill this gap by addressing a research question: "Does mobile money adoption improve maternal healthcare utilization of the poor?" The study conducts regression analysis of community- and mother-level fixed effects models. Statistical inference is conducted in order to assess the impact of mobile money adoption on maternal health-seeking behavior. As outcome 
variables, three dummy variables are used: if a mother achieves the WHO-recommended minimum ANC contacts (four visits), facility delivery, and delivery assisted by an SBA. The primary hypotheses that we test are whether mobile money adoption improves the uptake of those three types of maternal healthcare.

We find suggestive evidence of the positive impact of mobile money adoption on ANC-seeking behavior. The results from falsification tests and robustness checks support the validity of our empirical strategy, though the results do not lead us to reach definitive conclusions on the causal relationship. The results of heterogeneity analysis indicate that the effect of mobile money adoption is driven by households located far from the closest main road. The impact is also strong for households located in villages that did not initially have a higher-level health facility around their residential area. These results suggest that mobile money mitigates geographical barriers and encourages mothers to travel to and receive ANC at distant health facilities. On the other hand, the results failed to reject the null hypothesis of no mobile money effect on the facility delivery and the delivery assisted by SBAs.

This study contributes to financial inclusion literature and maternal health literature. The results suggest that mobile money as a tool of financial inclusion positively affects women's maternal health-seeking behavior. Thus, we provide suggestive evidence on a key channel-improving access to healthcare-through which financial inclusion contributes to achieving the Sustainable Development Goals. Also, maternal health researchers have been searching for an effective tool to motivate women from poor households to receive proper maternal care. Lack of money has been indicated as a critical problem. Adding to the existing tools such as giving cash incentives or providing access to microfinance, we show that mobile money has the potential to become a new tool to improve maternal and child health.

This paper proceeds as follows. Section 2 gives a brief background on mobile money and the maternal health service environment in Uganda. Section 3 presents key potential channels conveying the impact of mobile money adoption on health-seeking behavior. Section 4 presents the study design and data. Section 5 presents identification strategy and empirical results, including falsification tests, robustness checks, and heterogeneity analysis. Section 6 illustrates limitations. Section 7 gives the discussion.

\section{Context}

\subsection{Mobile Money Services}

Mobile money is an innovative, cheap, secure, and convenient medium that extends financial services even to the poor who have minimal access to formal financial institutions. At the most basic level, mobile money allows its users to make monetary transactions through mobile phones and, hence, to send and receive remittances, to buy goods, and to pay fees electronically. Mobile money mechanism needs a cash-in, cash-out infrastructure, which consists of a network of "agents" who take a small commission for turning cash into electronic value (and vice versa). Mobile money agents are usually existing local businesspersons selling airtime cards who chose the mobile money business as a diversification of their services. In 2015, Uganda had 33,845 agents [24], which was significantly larger than the number of automated teller machines (ATMs) operated by commercial banks (842) [25].

Sub-Saharan African countries began seeing the entry of mobile money services in 2007 and 2008. Mobile money services were established in Uganda in 2009; by mid-2015, Uganda had over 19.8 million mobile money users, which represents almost half of the population [26]. The high growth rate of mobile money users makes Uganda a good setting to study the impact of the technology on social welfare.

\subsection{Maternal Health Services in Uganda}

In line with the WHO guidelines, the Ministry of Health (MOH) of Uganda recommends that a woman have at least four ANC visits. During these visits, health experts detect health problems 
associated with pregnancy. In the event of any complications, more frequent visits are advised and admission to a higher quality health facility may be necessary. According to a study based on the Demographic and Health Surveys (DHS), 45 percent of women in rural Uganda for the period 2007-2011 made four or more ANC visits, while 55 percent of women delivered babies at health facilities [27]. Those figures are consistent with the data we use (the RePEAT study).

According to the clinical guideline of Uganda [28], ANC requires the following three components at all visits: addressing identified problems, checking blood pressure, and measuring the symphysis-fundal height (SFH) and fetal heart activity. In addition to those, the objective of ANC includes the following services as necessary: satisfying any insufficient nutritional, social, emotional, and physical needs of the pregnant woman; identification of high-risk pregnancy; and referral as appropriate for assessment of maternal well-being including ultrasound and vaginal (vulval) examination. A whole package of such services is called the comprehensive ANC and can only be secured at high-quality health facilities. In fact, according to the DHS report, in 2011, only 59 percent of mothers received blood pressure measurements, which is one of the required tasks of ANC [18]. This implies that many mothers did not visit health facilities of recommended quality. Women in rural areas are less likely to use such health facilities than those in urban areas [18].

According to the 2011 DHS report, 57 percent of deliveries in the five years preceding the survey took place at some health facilities while 42 percent of deliveries took place at home. Regarding delivery assistance, skilled providers assisted in the delivery of 57 percent of births while traditional birth attendants, relatives, friends, or nobody assisted the rest. The 2016 DHS report described the improvement of those figures. Seventy-three percent of live births in the five years preceding the survey were delivered in some health facilities, and a skilled provider conducted deliveries of almost the same proportion (74 percent) [29].

Table 1 presents the Ugandan government's classification of health facilities with the target population size and the geographical coverage [30]. The health facility of the lowest administration level with a physical establishment is a Health Center II (HCII). An HCII is supposed to be in every parish, which is the second smallest administrative unit in Uganda. This level of facility is not supposed to provide delivery care or comprehensive ANC, although sometimes $\mathrm{HCII}$ may receive emergency cases and provide partial ANC, which does not require laboratory testing. A Health Center III (HCIII) provides delivery and comprehensive ANC. This level of facility and the facilities of higher levels can provide maternal healthcare of the quality recommended by WHO.

The dominant type of health facility is publicly owned. There also exist a relatively small number of private or NGO health facilities, and their quality is wide-ranging from a lower level to a higher level.

Table 1. Public health facilities in Uganda.

\begin{tabular}{|c|c|c|c|c|}
\hline $\begin{array}{l}\text { Types of Health } \\
\text { Center (HC) }\end{array}$ & Area to Cover & Target Population & $\begin{array}{l}\text { Definition in } \\
\text { This Paper }\end{array}$ & Notes \\
\hline $\mathrm{HCI}$ & $\begin{array}{c}\text { A village } \\
\text { (or Local Council I) }\end{array}$ & 1000 & \multirow{2}{*}{$\begin{array}{c}\text { Lower-level } \\
\text { health facilities }\end{array}$} & $\begin{array}{l}\text { HCIs comprise of village health } \\
\text { teams which provide } \\
\text { community-based preventive and } \\
\text { promotive services. }\end{array}$ \\
\hline $\mathrm{HCII}$ & A parish & 5000 & & $\begin{array}{l}\text { HCIIs provide preventive and } \\
\text { curative health services, outreach } \\
\text { care, and emergency deliveries. }\end{array}$ \\
\hline HCIII & A subcounty & 20,000 & \multirow{5}{*}{$\begin{array}{c}\text { Higher-level } \\
\text { health facilities }\end{array}$} & \multirow{5}{*}{$\begin{array}{c}\text { This level of facilities can provide } \\
\text { maternal healthcare of the quality } \\
\text { recommended by WHO, } \\
\text { which includes in-patient and } \\
\text { laboratory services. }\end{array}$} \\
\hline HCIV & A county & 100,000 & & \\
\hline HCV (general hospital) & A district & 500,000 & & \\
\hline Regional hospital & A region & $2,000,000$ & & \\
\hline National hospital & $\begin{array}{l}\text { Located in the } \\
\text { capital city }\end{array}$ & - & & \\
\hline
\end{tabular}


The government's health inventory database indicates that there had been a significant increase in the number of health facilities in Uganda between 2002 and 2015; the number of facilities increased from about 2500 to 5000 [21]. While the increase of HCIIs mostly drove the increase in the number of health facilities, the higher-level health facilities also increased.

In this paper, a lower-level health facility means HCII. A higher-level health facility includes HCIII, HCIV, government hospitals, and private or NGO health facilities. Both of the indicators are constructed based on the RePEAT survey.

\section{Key Potential Channels of Mobile Money Impact}

We examine the impact of mobile money adoption on healthcare service utilization, specifically on the use of maternal care among Ugandan women. Why would adoption of mobile money help mothers receive maternal care? To receive maternal care, the expectant mother has to bear the cost, such as payment at a health facility, transportation cost, and opportunity cost. Such financial barriers are well documented in the literature as a crucial problem on access to maternity care [31]. In the context of rural Uganda, as shown in Table 2, to receive ANC, the expectant mother had to pay around 1500 Ush in 2012 and 5000 Ush in 2015; USD was equivalent to Uganda shilling 2557 in financial years 2011-12 [32]. Considering that a typical rural household spent 3000 Ush for a meal, one can see that the ANC cost is not cheap. Besides, an expectant mother had to pay the transportation cost. According to a study which investigates modes of transport for making maternal care visits in Uganda for the period 2012-2013, 63 percent of Ugandan women used motorcycle taxis [33]. The RePEAT study also shows that an expectant mother had to spend around one hour to reach the place for ANC and had to wait for another one hour (Table 2). In this section, we discuss the potential channels of the effect of mobile money adoption: effect on liquidity constraint and income effect. We also describe how past studies have attempted to overcome the financial barrier to maternity care.

\subsection{Effect on Liquidity Constraint}

The 2011 Uganda Demographic Health Survey asked women what factors would be a significant problem for them in seeking medical care [18]. Almost half of the women said that preparing money to pay for treatments was a problem in accessing healthcare, while almost as many said that distance to a facility was a problem. The existing literature attempts to find effective ways to motivate mothers to receive ANC by giving them cash transfer or vouchers [15,16,34,35]. Dupas [9] also argues that liquidity constraint and lack of saving technology hinder the poor from seeking healthcare. While Tarozzi et al. [11] show that microfinance is effective for encouraging poor households to take health-seeking behavior, Dupas and Robinson [10] find that providing a safe saving tool increases health savings significantly.

Mobile money eases liquidity constraints of its users facing financial problems by giving them a means to receive immediate cash transfer from family members, relatives, or friends. It is often used as a tool for savings, which also relaxes liquidity constraints among rural residents who do not have access to other inexpensive and effective savings technologies. Indeed, mobile money users receive a larger amount of remittances more frequently from migrant workers living in cities and also save more money than nonusers. By using a dataset of rural Ugandan households, Munyegera and Matsumoto [4], and Tabetando and Matsumoto [36] provide evidence of the causal relationship between mobile money use and the amount of remittances or the number of remittances. Further, Munyegera and Matsumoto [7] show evidence of the correlation between mobile money use and the likelihood of having savings. Those studies used a rural Ugandan dataset, which is the same dataset used in this study. Among those, the studies about remittances-they used the household fixed effects model-report that both the probability of receiving remittances and the amount of remittances increase significantly for mobile money users compared to nonusers. By restricting the samples to those used in this study — the households which reported pregnancy experiences-we show a regression table in Appendix F (Table A6) indicating that mobile money users have better access to 
remittances. The table is essentially a replicate-with the restricted samples-of the tables shown in past studies $[4,36]$. For space reasons, we do not describe details on the positive relationship between mobile money use and remittances or savings; they are argued in detail in the studies above.

One can see the vital potential channels of the effect of mobile money on poor households. Easing their liquidity constraint by mobile money services may change the health-seeking behavior of pregnant women. Financial inclusion tools, including microfinance, have been found to support uptake of health services. Thus, the adoption of mobile money as a tool of financial inclusion may also contribute to making cash more accessible to poor households and to encouraging women to receive maternal care.

\subsection{Income Effect}

In addition to easing liquidity constraint for the poor to use health services, mobile money adoption among rural households may have an income effect on demand for healthcare services corresponding to an increase in remittance receipt and, hence, may change their health-seeking behaviors. If maternal healthcare is a normal good, income increase leads to a higher demand for such services. By using the dataset of rural Ugandan households, which is the same dataset used in this study, Munyegera and Matsumoto [4] show that the amount of remittance that rural households receive increases for mobile money users compared to nonuser counterparts. The increase in income may change an expectant mother's maternal care-seeking behavior. Specifically, such an increase in income may lead to a change in the mode of transport for maternal care; a past study of Uganda reports that women in the wealthiest quintile were more likely to travel by car or truck than their less-wealthy counterparts [33]. Having broader options for the mode of transport may change an expectant mother's maternal care-seeking behavior.

In this paper, we cannot disentangle the effect on liquidity constraint from the income effect. The mobile money adoption effect in this paper includes both of the effects.

\section{Data and Study Design}

We created a dataset based on household-level panel surveys of rural Uganda. We utilize retrospective questions on maternal care-seeking behavior asked in the surveys. We construct an original dataset of pregnancy reports with a panel structure; mothers can report their experiences for each of their past pregnancies. Thus, pregnancy reports have a panel structure at the mother level. The mother-level panel structure is a key feature of this study because it is useful for identifying the causal relationship between mobile money usage and maternal care-seeking behavior. The recall panel data allows us to use the difference-in-difference fixed effects model (at the community and mother levels in our case), which is a rigorous microeconometrics approach used in many other mobile money studies (for example, References [2,3]). In this section, we first explain the details of the household-level panel surveys that we use and then describe how we construct our original recall panel data.

\subsection{Household-Level Panel Survey}

Panel data from household surveys collected in Uganda as part of the RePEAT project is used in this study. The RePEAT project was jointly administered by Makerere University, Foundation for Studies on International Development (FASID), and National Graduate Institute for Policy Studies (GRIPS). Among the five survey rounds in 2003, 2005, 2009, 2012, and 2015, we use the data of 2009, 2012, and 2015 because the first mobile money service was established in March 2009 by Mobile Telephone Network. Among those three rounds, the data of 2012 and 2015 are the primary source of our study; the two rounds collected the information on maternal health-seeking behavior. The 2009 data is used as a supplement to obtain household characteristics and the GPS location of households.

The RePEAT data consists of around 940 rural households. In the 2003 survey, 94 villages were sampled; ten households were randomly selected from each of the villages, which are scattered in three regions (central, east, and west). In the following surveys, new households were sampled in response 
to attritions following the sampling method described above. At the round for 2012, 911 households were surveyed; the average attrition rate between the rounds of 2003 and 2012 was low at $8.0 \%$. At the round for 2015, 847 households were surveyed; the attrition rate from the round for 2012 to 2015 was also low at 7\% (see Appendix A for more details on the round for 2015).

\subsection{Retrospective Reports on Maternal Health-Seeking Behavior}

The RePEAT survey questionnaires include questions about maternal health-seeking behavior in the 2012 and 2015 rounds; the data has 1684 pregnancy-level observations from 586 households. The location of 585 households with GPS information from the RePEAT study is shown in Figure 1. Mothers aged 15-56 or females aged 15-56 at the time of the survey who have experience with any pregnancies were asked about their delivery history between 2001 and the survey year in each of the survey rounds (2012 or 2015). In round 2012, for mothers who were interviewed in 2005, pregnancy experiences between 2005 and 2012 were asked. For the rest of the mothers, pregnancy experiences between 2001 and 2012 were asked. When there were more than two mothers in a household, two mothers were randomly selected and asked to answer the survey. In round 2015, the survey prioritized interviewing mothers who were interviewed in 2012 (or supposed to have been interviewed in 2012). If there were fewer than two such mothers in the household, the interviewer conducted the survey with additional mother(s) in the household if any (see Appendix A for more details).

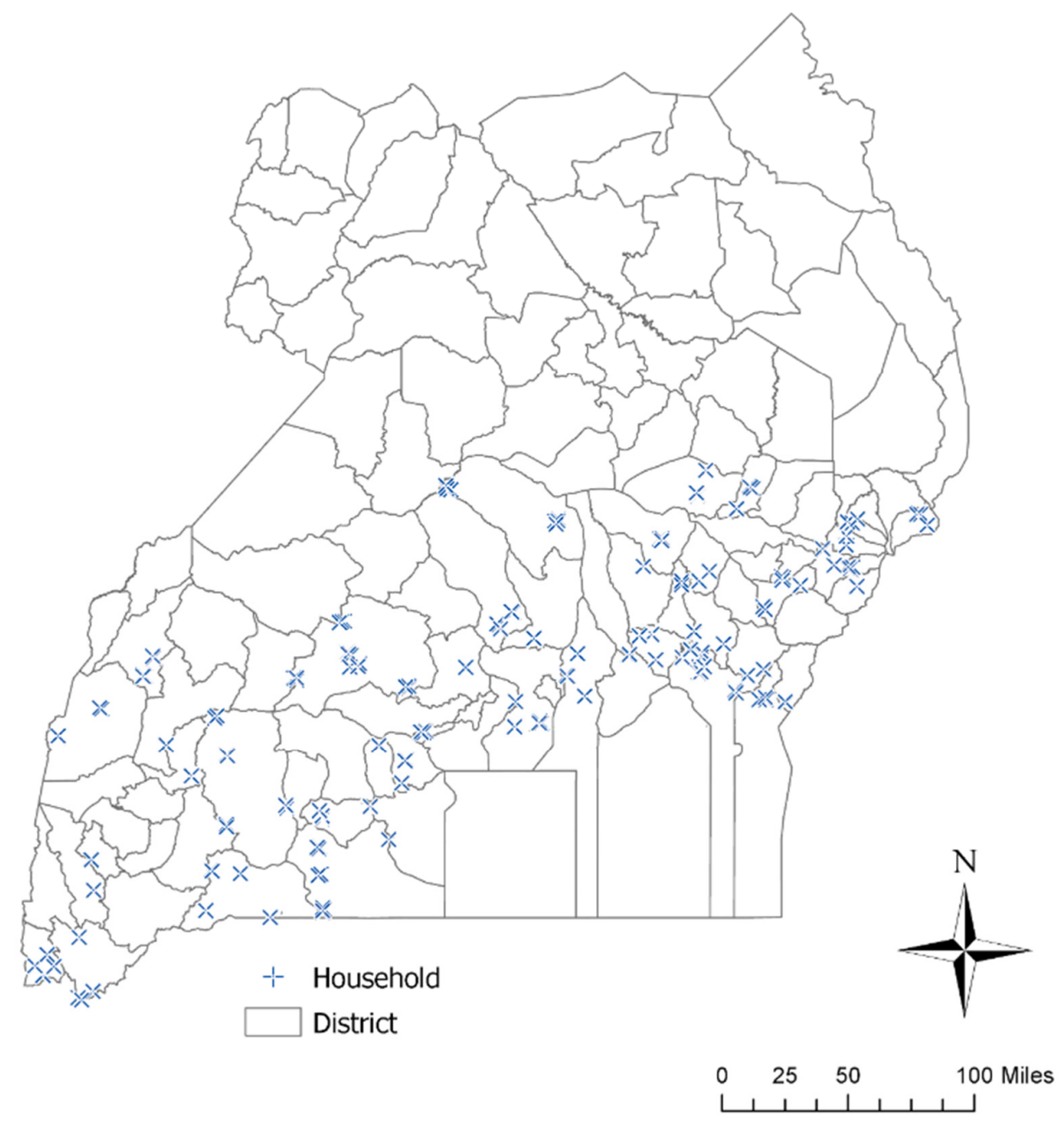

Figure 1. Location of households and the 2010 district boundaries in Uganda. Sources: Uganda Bureau of Statistics, the RePEAT (Research on Poverty, Environment, and Agricultural Technology) study 2009/2012/2015. 
The RePEAT survey questionnaires also include questions about adoption of mobile money in the 2012 and 2015 rounds. In 2012, a household head was first asked whether he/she or the spouse uses mobile money. Next, he/she was asked about possession of a mobile money account and then the year in which he/she opened the account. In 2015, each household head was asked about the year in which any of the household members started to use mobile money. We combined the information from the 2012 and 2015 rounds and constructed a variable indicating mobile money usage by a household at the annual level.

We use retrospective reports of both deliveries and mobile money adoption. On deliveries, a few mothers reported seven past pregnancy experiences responding to a survey round. This raises concerns that it may be prone to recall errors. However, studies on maternal health-seeking behavior using retrospective reports generally do not consider that recall errors are severe [21,37-39]. Some of the studies rely on Beckett et al. [40], who investigated the usefulness of long-term retrospective reports by using Malaysian data from the 1970s and 1980s.

Becket et al. [40] reported two essential findings: "data quality deteriorates with the length of the recall period" and "the more salient an event is to the respondent, the more accurate its report." Their study argues that information on salient life events such as pregnancy experience for live-born children is less prone to recall errors. Thus, two of our primary outcome variables, facility delivery and the presence of SBAs, are likely to be less prone to recall errors. However, we cannot rely on Beckett et al.'s findings if somebody other than the mother herself answered questions because the delivery is not a salient event for the respondent anymore. To keep the data quality better, we exclude delivery reports answered by family members other than mothers themselves. This decreases the number of observations on facility deliveries from 1650 to 1231 (1684 to 1247 for deliveries by SBAs).

Detailed information such as number of ANC visits made in each of the three trimesters would be probably more prone to recall errors. Thus, one of our primary outcome variables-ANC visit-is more likely to be prone to recall errors. The DHS is likely to avoid such a problem by restricting questions on ANC to the latest pregnancy experience within the past five years [18]. Similarly, to create ANC-related variables, in our data, we restrict the pregnancy reports to those of the past five years from the survey year. We also exclude the information on ANC answered by family members other than mothers themselves. Those decrease the number of observations on ANC from 1634 to 844 of 399 households of 92 villages in 120 parishes (see Tables $\mathrm{A} 3$ and $\mathrm{A} 4$ in the Appendix $\mathrm{F}$ for full sample regressions' results). Our treatment also follows the recommendation made in Becket et al. [40]; the study suggests varying recall periods of variables with saliency. In our case, we judge that delivery reports are more salient than ANC reports.

Table 2 reports summary statistics for the analysis sample of each survey round. Between 2012 and 2015, the mobile money user household rate increased from 39.8 percent to 54.2 percent. In contrast, the bank account user percentage showed no increase. The percentage of mothers who received recommended ANCs at a higher-level health facility increased from 21.7 percent to 30.0 percent. The number of ANC visits (including lower-level health facilities or any other facilities providing insufficient maternal care services such as drugstores or homebirth), however, showed no increase. Those figures imply that more mothers had come to receive ANC at good quality facilities. Both the cost spent on receiving ANC and the transportation cost spent increased. In contrast, the cost spent on delivery showed a relatively moderate increase. The percentage of mothers who received delivery services by a skilled provider or at a good quality facility also increased. 
Table 2. Summary statistics.

\begin{tabular}{|c|c|c|c|c|c|c|}
\hline \multicolumn{7}{|c|}{ (a) Mother/household/village level characteristics } \\
\hline & \multicolumn{3}{|c|}{2012 ROUND } & \multicolumn{3}{|c|}{2015 ROUND } \\
\hline & $\mathbf{N}$ & Mean & SD & $\mathbf{N}$ & Mean & SD \\
\hline Age & 386 & 31.8 & 8.21 & 136 & 36.4 & 7.16 \\
\hline Education & 386 & 5.17 & 3.54 & 136 & 5.29 & 3.4 \\
\hline 1 if she is the household head & 386 & 0.0829 & 0.276 & 136 & 0.0735 & 0.262 \\
\hline \multicolumn{7}{|c|}{ Household (HH) level characteristics } \\
\hline Head Education & 351 & 6.03 & 3.51 & 131 & 5.64 & 3.78 \\
\hline Total value of assets (Ush) & 358 & $1,077,274$ & $1,799,862$ & 131 & $1,492,355$ & $6,734,598$ \\
\hline Land holding size (acre) & 359 & 5.64 & 12.4 & 133 & 6.21 & 13.8 \\
\hline 1 if having non-agriculture business & 359 & 0.543 & 0.499 & 134 & 0.552 & 0.499 \\
\hline Number of $\mathrm{HH}$ members & 359 & 11.3 & 4.62 & 134 & 12.9 & 5.76 \\
\hline \multicolumn{7}{|c|}{ Village level characteristics } \\
\hline Number of higher-level health facilities around village ( $\leq 5$ miles) & 89 & 1.37 & 1.05 & 69 & 1.57 & 1.08 \\
\hline Number of higher-level health facilities* around village ( $\leq 5$ miles) & 89 & 1.46 & 1.2 & 69 & 1.61 & 1.14 \\
\hline Number of lower-level health facilities around village ( $\leq 5 \mathrm{miles})$ & 89 & 0.494 & 0.624 & 69 & 0.551 & 0.631 \\
\hline \multicolumn{7}{|c|}{ (b) Pregnancy level information } \\
\hline & \multicolumn{3}{|c|}{2012 ROUND } & \multicolumn{3}{|c|}{2015 ROUND } \\
\hline & $\mathbf{N}$ & Mean & SD & $\mathbf{N}$ & Mean & SD \\
\hline \multicolumn{7}{|c|}{ Pregnancy level information } \\
\hline Year of pregnancy termination & 692 & 2009 & 1.68 & 152 & 2014 & 1.13 \\
\hline
\end{tabular}


Table 2. Cont.

\begin{tabular}{|c|c|c|c|c|c|c|}
\hline \multicolumn{7}{|c|}{ (b) Pregnancy level information } \\
\hline & \multicolumn{3}{|c|}{2012 ROUND } & \multicolumn{3}{|c|}{2015 ROUND } \\
\hline & $\mathbf{N}$ & Mean & SD & $\mathbf{N}$ & Mean & SD \\
\hline Number of ANC visits & 661 & 4.94 & 2.77 & 150 & 4.86 & 3.01 \\
\hline Number of ANC visits at a higher-level health facility & 683 & 3.85 & 3.25 & 150 & 4.11 & 3.35 \\
\hline 1 if received recommended ANC (4 times,1-1-2, at a higher-level health facility) & 688 & 0.217 & 0.412 & 150 & 0.3 & 0.46 \\
\hline 1 if received ANC 2 times within third trimester at a higher-level health facility & 686 & 0.552 & 0.498 & 150 & 0.513 & 0.501 \\
\hline Cost of making an ANC visit (Ush) & 653 & 1534 & 7450 & 149 & 5526 & 12,280 \\
\hline Transportation cost of making an ANC visit (Ush) & 600 & 1027 & 2100 & 146 & 1710 & 3088 \\
\hline Travel time for ANC & 654 & 47.9 & 45.1 & 149 & 40.6 & 35.6 \\
\hline Waiting time for ANC & 658 & 72.8 & 74.6 & 148 & 69.7 & 82.5 \\
\hline 1 if delivered at a higher-level health facility & 681 & 0.382 & 0.486 & 150 & 0.5 & 0.502 \\
\hline \multicolumn{7}{|c|}{ (c) Village level time invariant characteristics } \\
\hline & & & & (1) & (2) & (3) \\
\hline Village level time invariant characteristics & & & & $\mathbf{N}$ & Mean & SD \\
\hline Time for driving to nearest district town in dry season & $\min )$ & & & 117 & 36.2 & 30.1 \\
\hline 1 if road condition in a dry season is better than an averag & village & & & 117 & 0.615 & 0.489 \\
\hline
\end{tabular}


Table 2. Cont.

\begin{tabular}{|c|c|c|c|}
\hline \multicolumn{4}{|l|}{ (d) Household-level time-invariant characteristics } \\
\hline & (1) & (2) & (3) \\
\hline Household $(\mathrm{HH})$ level time invariant characteristics & $\mathbf{N}$ & Mean & SD \\
\hline 1 if $\mathrm{HH}$ is more than 1.3 mile (mean) away from the closest road & 585 & 0.347 & 0.476 \\
\hline Distance (mile) between village reference point and $\mathrm{HH}$ & 585 & 0.43 & 0.635 \\
\hline 1 if village reference point is more than 0.4 mile (mean) away from $\mathrm{HH}$ location & 585 & 0.362 & 0.481 \\
\hline 1 if altitude difference from $\mathrm{HH}$ to village reference point is over $14.6 \mathrm{~m}$ (mean) & 585 & 0.26 & 0.439 \\
\hline 1 indicating that $\mathrm{HH}$ is located at an area largely occupied by water & 585 & 0.00684 & 0.0825 \\
\hline
\end{tabular}

Sources: The RePEAT study 2009/2012/2015, Uganda Bureau of Statistics, DIVA-GIS. (1) According to the Bank of Uganda's Annual Report 2012, USD was equivalent to Uganda shilling 2557 in financial years 2011-12. (2) Age is calculated at the year of pregnancy terminated. We restrict the pregnancy reports to those of the past five years from the survey year. We also exclude the pregnancy reports answered by family members other than mothers themselves. (3) Panel B shows the summary statistics of all the 117 villages covered by the RePEAT study 2009/2012/2015. Most of the time for driving to the nearest district town in the dry season was from the 2015 round. Three villages' information were complemented with the data of the 2012 round. (4) Panel C shows summary statistics of all the 585 households with GPS information of the rounds for 2012 and 2015, which reported at least one pregnancy information. (5) The source of the data of the location of the closest road from households and areas largely occupied by water is the Uganda Bureau of Statistics. The source of the data of altitude is DIVA-GIS. The source of the rest of the data is the RePEAT study. (6) The information on the household characteristics is only available for the survey years. The values of the survey year are copied and assigned to the non-survey years for the regressions (details can be found in the Table A1 in Appendix B). The information on the adoption of mobile money by a household is the exception; it is available at the annual level. Regarding village characteristics, the number of health facilities is available at the annual level. However, the numbers of lower-level health facilities of 2013-2015 are available for only 59 villages in the RePEAT study. Those of the rest of the villages are missing. To preserve observations in 2013-2015, we conducted interpolation by copying the numbers of 2012 to $2013-2015$ for those villages. (7) Higher-level health facilities with asterisks provide delivery care. Higher-level health we conducted interpolation by copying the numbers of 2012 to $2013-2015$ for those villages. (7) Higher-level health facilities with asterisks provide delivery care. Higher-level health
facilities without asterisks provide comprehensive ANC. The RePEAT surveys collected the information in villages from informants. We use each of the variables to control for the regressions on corresponding outcome variables. 


\section{Empirical Results}

\subsection{Hypotheses}

To examine the impact of mobile money adoption on maternal care utilization, we first examine the following three hypotheses. Considering the key potential channels through which mobile money would help mothers receive maternal care, we hypothesized a positive mobile money effect on maternal care utilization.

Hypothesis 1 (H1). Pregnant women from mobile money users' households are more likely to avail themselves of recommended ANC compared to women from nonusers' households.

Hypothesis 2 (H2). Pregnant women from mobile money users' households are more likely to receive delivery service at a WHO-recommended-level (higher-level) health facility.

Hypothesis 3 (H3). Pregnant women from mobile money users' households are more likely to receive delivery service from an $S B A$.

In the subsection titled "Heterogeneity analysis" under the section of "Empirical results," we conduct heterogeneity analysis of the positive mobile money effect. We examine two additional hypotheses to study what kind of household mobile money benefits more.

\subsection{Empirical Strategy: Difference-in-Difference Fixed Effects Model}

There are four major empirical techniques used in observational studies of microeconometrics to identify causal effects of policy interventions: difference-in-difference approach, instrumental variables (IV) approach, regression discontinuity design approach, and matching methods [41]. In this study, we use the difference-in-difference approach to identify the causal effect of a policy intervention-delivery of mobile money services-by utilizing the panel structure of the dataset. In this section, we explain how a difference-in-difference approach works based on Angrist and Pischke [42].

In experimental studies, economists use a randomized control trial; this is essentially a simple comparison of the mean outcome in treatment and control groups-the "difference" estimator. When one conducts a randomized control trial, the randomization ensures that the "difference" estimator provides an unbiased and consistent estimate of the causal effect.

In observational studies with cross-sectional data, economists try to find equivalents of treatment and comparison groups in which everything other than the policy intervention is assumed to be the same. However, finding equivalent treatment and control groups is often difficult and hard to test.

In observational studies with panel-structure data (this study), one can conduct a causal inference with a more realistic assumption: the unobserved differences are the same over time after controlling observed characteristics. In this case, one can use data before the treatment to estimate the "before" difference between treatment and comparison groups and then to compare the difference with the estimate of the "after" difference of the period after the treatment group received the treatment. This estimator is called the "difference-in-difference" estimator because it takes a difference between "before" and "after" differences. A graph can make the idea clearer (Figure 2).

For interpreting the difference-in-difference estimator as a causal impact, an assumption is required: the trend in outcome variables $(\mathrm{Y})$ would have been the same in both the treatment and comparison groups in the absence of the treatment. One can test this assumption by checking whether, in earlier periods, the assumption of a common trend seems to be satisfied. In this study, we test the common trend assumption in the section titled "Falsification tests" by examining whether there are differential pre-trends between treatment and comparison groups. If a placebo mobile money indicator-it takes one before the beginning of mobile money services—indicates that mobile money users' maternal 
health-seeking behavior was improved even before they start using mobile money, one does not believe that the common trend assumption is satisfied.

When there is not a single point of the year in which some households receive a policy intervention but the treatment is received in different timings, one can use a slightly modified model: difference-in-difference fixed effects model. In this study, the treatment-use of mobile money-began at different times for each household. Thus, we apply the difference-in-difference fixed effects model. We include community- or mother-fixed effects, which is essentially communityor mother-specific dummies, in the estimated equations. In this way, we control for the "before" differences between communities or mothers. More specifically, by using fixed effects, we compare a mother (or a community) before the treatment-mobile money adoption-and the same mother after the treatment to estimate the causal impact of mobile money use.

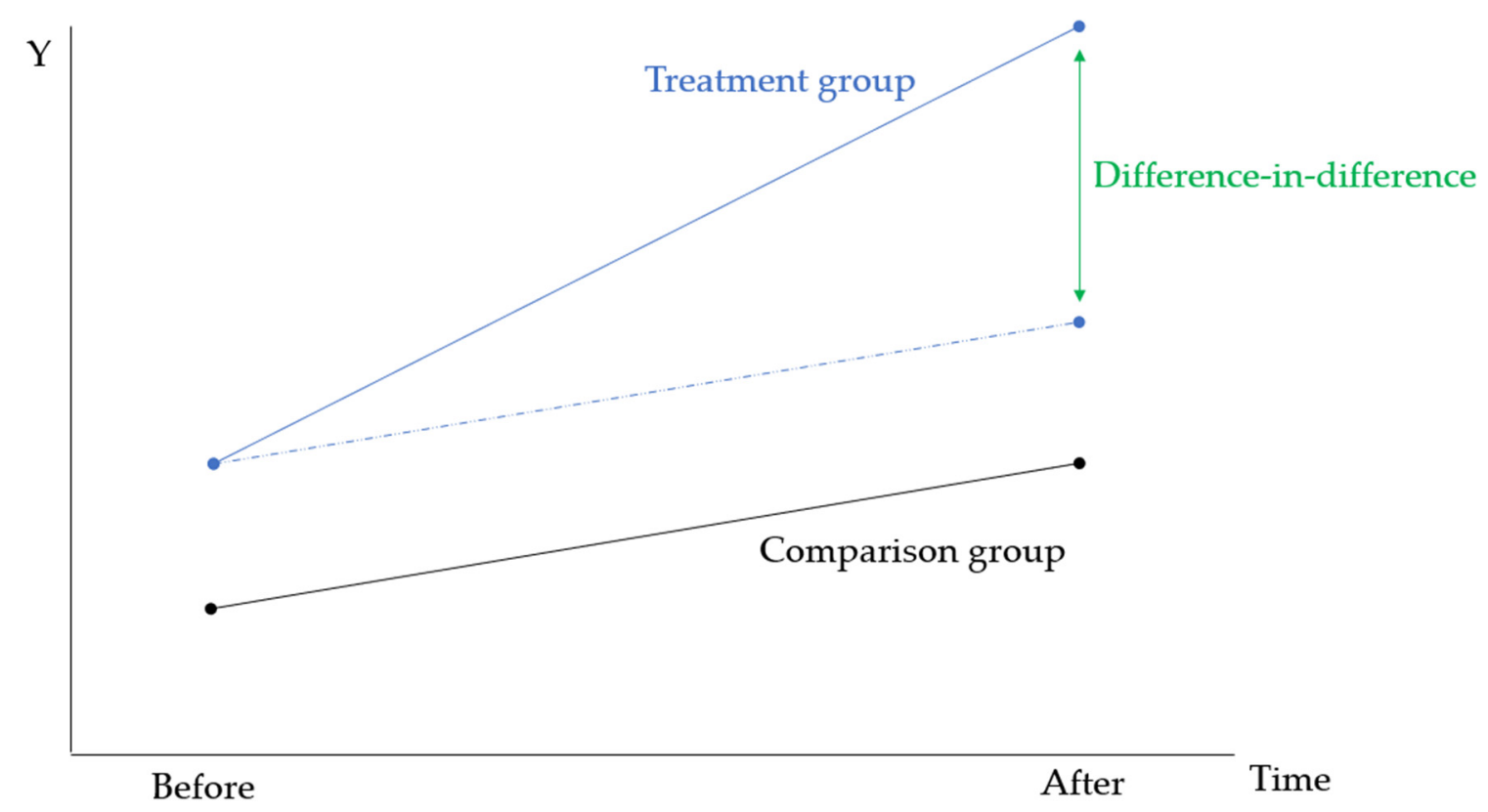

Figure 2. Difference-in-difference approach.

\subsection{Estimation}

\subsubsection{Empirical Model}

The basic empirical model to estimate the impact of mobile money adoption among rural households on health-seeking behaviors especially for pregnant women is described as the following equations:

$$
\begin{aligned}
& y_{i j h k t}=\mu \text { Mmone } y_{h k t}+\psi X_{j h k t}+\alpha_{j}+\eta_{d t}+v_{i j h k t}, \\
& y_{i j h k t}=\mu M \text { mone } y_{h k t}+\psi X_{j h k t}+\gamma_{k}+\eta_{d t}+v_{i j h k t},
\end{aligned}
$$

where $y_{i j h k t}$ is a dependent variable such as a dummy variable which indicates the take-up of a specific maternal healthcare at pregnancy $i$ is followed by mother $j$ of household $h$ living in parish $k$ at time period t. Mmone $y_{h k t}$ is a dummy variable which is one if household $h$ uses mobile money at time period $t$. The coefficient $\mu$ is the parameter of interest. Specification (1) includes district-by-time dummies $\left(\eta_{d t}\right)$ to control for the annual nation- and district-wide changes, events, or shocks which might have affected the ease of maternal healthcare. The specification also includes mother-fixed effects $\left(\alpha_{j}\right)$. Specification (2) is a relaxed version of specification (1). Specification (2) uses parish-fixed effects $\left(\gamma_{k}\right)$ instead of mother fixed effects.

$X_{j h k t}$ is a vector of controls, including individual characteristics and household characteristics which might ease making health visits. The individual characteristics include maternal age at delivery, years of 
education, and parity. The household characteristics include mobile phone ownership, number of household members, number of migrants, log of aggregated asset value, log of the size of landholding, household head's years of education, and ownership of any non-agricultural business. We also control for the household-level time-invariant geographic characteristics. The geographic information is likely to capture the remoteness which could affect maternal care utilization. These include a dummy variable which is one if the location of a household is relatively far from the closest main road. It is one if the distance from a household to the closest road is larger than 1.3 miles, which is the mean of the sample. The controls also include a dummy variable which is one if a household location is relatively far from the center of the village and a dummy variable which is one if the altitude of a household location is relatively far from the center of the village. Those dummies are one if the distance is longer than the mean of the sample. We use the reference points of each village recorded in the RePEAT survey as the location of the center of the village. The reference points are the places used for having meetings with informants in the village by enumerators of the RePEAT study. Those are buildings such as village offices, schools, or churches. Additionally, the geographic information of a household includes a dummy variable which is one if a household is located at an area occupied mainly by the water surface.

$X_{j h k t}$ also includes village characteristics that affect access to healthcare. Those include three dummies for the number of higher-level health facilities and two dummies for the number of lower-level health facilities within five miles from the reference point of each village (three miles instead of five did not change the results qualitatively). Those dummies are time-variant variables. We also control for a dummy indicating the road condition in a dry season from each village to the closest district. It takes the value of one if the driving time to the closest district is shorter than the sample average. This variable is time invariant (see Appendix $C$ for more details).

Mother-fixed effects capture mother-specific time-invariant characteristics such as preference towards healthcare, cultural background, and relationship with family members. The previous literature studies the importance of unobservable characteristics. For example, Allendorf [39] points out that a good relationship between a woman and her family members is essential for encouraging a mother to seek maternal care. As long as a woman continues living in the same parish, mother-fixed effects also control for parish-specific characteristics such as the cultural background or the social norm. Meanwhile, parish-fixed effects do not control for mother-specific characteristics. Thus, the mother-fixed effect model is our preferred specification.

Using difference-in-difference-fixed effect models require us to show that there is no concern about having pre-trend. We answer to this concern by conducting falsification tests. We also argue other types of endogeneity problems in the section named "Potential endogeneity."

\subsubsection{Outcome Variables}

One of the primary outcome variables is a dummy variable, which is one if a mother satisfies the take-up of ANC in line with the recommendation of WHO. The recommendation requires at least four ANC visits in total (since 2016, eight visits is recommended). It also requires a mother to attend ANC at least one time in the first trimester, one time in the second trimester, and two times in the third trimester. Furthermore, it requires a mother to take ANC at a particular quality health facility. In Uganda, health facilities for which quality is higher than Health Center III satisfy the requirement. Due to the data limitation, the quality of a private health facility where women visited is not available. We included private health facilities in higher-level health facilities. Hereafter, we denote making ANC in the way recommended by WHO as take-up of recommended ANC as used in Lawn et al. [27]. A mother who seeks ANC at a low-quality facility such as a drugstore or a community health worker office is not treated as one by the dummy variable of recommended ANC.

This study also covers two delivery-related variables, a dummy variable which is one if a mother received delivery service at a higher-level health facility and another dummy variable which is one if a mother received delivery service from an SBA. The three variables above are chosen as 
outcome variables because they attracted significant attention in the previous studies of maternal health $[16,21,35]$.

Descriptive statistics of stratified samples by mobile money adoption status are shown in the Table A2 in Appendix D. Many pregnancy-related variables show apparent differences between mobile money users and nonusers. For example, the proportion of delivery by an SBA is 81.3 percent for mobile money users, while that for nonusers is 61.4 percent. However, this might be because of self-selection into using mobile money-some articles report sociodemographic factors that correlate with adoption of mobile money: for example, age, education, and poverty level (for example, Reference [43]). In the empirical work, we test whether, in those differences, a real effect of mobile money adoption exists after excluding the effect of time, location, and other endogenous variables.

\subsection{Mobile Money Impact on Take-Up of Recommended ANC}

Table 3 presents the regression results of specifications (1) and (2). Column 1 reports ordinary least squares (OLS) results with no controls for comparison; in column 2, OLS results with the year dummies are reported. As the receiving rate of maternal care has been gradually improved year by year, year dummies change the significance level of the coefficient of interest to the ten percent level. For example, more and more health facilities have been built in Uganda, and the distance to the closest health facility from a household has gotten smaller and smaller during the study period. Column 3 controls for the full set of covariates and district-by-time dummies. The district-by-time fixed effects can capture any annual changes in the environment, which may affect the uptake of maternal healthcare, at the district level. The covariates include individual characteristics, household characteristics, and village characteristics, which could affect the ease of taking maternal healthcare. The village characteristics include a set of dummies indicating the number of higher-level health facilities and lower-level health facilities within five miles from each village to control for the supply-side improvement of healthcare (not shown for brevity). The estimate of the coefficient of interest is similar when we include parish-fixed effects in column 4 (specification (1)). The parish-fixed effects model shows the estimate significant at the five percent level. Finally, we take into account mother-fixed effects in column 5. The estimate of the coefficient of interest is similar to that of column 4 , and the estimate is significant at the ten percent level. Altogether, the results in column 1 through column 5 suggest that pregnant women from mobile money users' households are more likely to avail themselves of recommended ANC compared to women from nonusers' households. The magnitude of the effect of increasing the probability of making recommended ANC is likely to be around ten percentage points (for reference, the unconditional attendance rate of recommended ANC in 2009 was 23.8 percent). The estimated coefficients of the number of migrants in households are not significant. Considering the main mechanism of the mobile money impact-migrants send remittances, and households use the money received for maternal care-this coefficient is expected to be positive and significant. This is probably because of the measurement error caused by the timing of the number of migrants measured-the number of migrants was measured not annually but only in the survey rounds: 2009, 2012, and 2015. Thus, the estimate could be attenuated due to the measurement error. 
Table 3. Recommended ANC.

\begin{tabular}{|c|c|c|c|c|c|}
\hline \multicolumn{6}{|c|}{ Outcome Variable: 1 If Mother Received Recommended ANC (4 Times, 1-1-2). } \\
\hline & (1) & (2) & (3) & (4) & (5) \\
\hline \multicolumn{6}{|l|}{ Variables } \\
\hline 1 if $\mathrm{HH}$ used mobile money & $\begin{array}{l}0.121^{* * *} \\
(0.0413)\end{array}$ & $\begin{array}{l}0.0915 * \\
(0.0473)\end{array}$ & $\begin{array}{l}0.137 * * \\
(0.0607)\end{array}$ & $\begin{array}{l}0.117 * * \\
(0.0491)\end{array}$ & $\begin{array}{c}0.108 * \\
(0.0585)\end{array}$ \\
\hline Years of education (mother) & & & $\begin{array}{c}-0.00336 \\
(0.0101)\end{array}$ & $\begin{array}{l}-0.0037 \\
(0.0139)\end{array}$ & \\
\hline Age (mother) & & & $\begin{array}{c}-0.0027 \\
(0.00184)\end{array}$ & $\begin{array}{l}0.000993 \\
(0.00199)\end{array}$ & $\begin{array}{c}0.00339 \\
(0.00625)\end{array}$ \\
\hline Parity & & & $\begin{array}{c}-0.0092 \\
(0.017)\end{array}$ & $\begin{array}{c}-0.00527 \\
(0.0252)\end{array}$ & $\begin{array}{l}0.131 * \\
(0.0652)\end{array}$ \\
\hline 1 if $\mathrm{HH}$ had mobile phone & & & $\begin{array}{l}-0.0277 \\
(0.0695)\end{array}$ & $\begin{array}{l}-0.0201 \\
(0.0693)\end{array}$ & $\begin{array}{c}-0.0366 \\
(0.114)\end{array}$ \\
\hline Number of $\mathrm{HH}$ members & & & $\begin{array}{c}0.00191 \\
(0.00344)\end{array}$ & $\begin{array}{c}0.00154 \\
(0.00459)\end{array}$ & $\begin{array}{c}0.0448^{* *} \\
(0.0175)\end{array}$ \\
\hline Number of migrants in $\mathrm{HH}$ & & & $\begin{array}{l}0.00582 \\
(0.0192)\end{array}$ & $\begin{array}{c}-0.00726 \\
(0.0179)\end{array}$ & $\begin{array}{c}-0.0431 \\
(0.04)\end{array}$ \\
\hline Asset value of $\mathrm{HH}(\log )$ & & & $\begin{array}{c}0.0143 \\
(0.0221)\end{array}$ & $\begin{array}{c}0.0165 \\
(0.0248)\end{array}$ & $\begin{array}{c}-0.0402 * \\
(0.0214)\end{array}$ \\
\hline Land size of $\mathrm{HH}(\mathrm{log})$ & & & $\begin{array}{c}0.00333 \\
(0.00746)\end{array}$ & $\begin{array}{l}0.000247 \\
(0.00994)\end{array}$ & $\begin{array}{c}-0.0229 * * \\
(0.0111)\end{array}$ \\
\hline $\mathrm{HH}$ head education (year) & & & $\begin{array}{c}0.00541 \\
(0.00873)\end{array}$ & $\begin{array}{l}0.00246 \\
(0.0107)\end{array}$ & $\begin{array}{c}0.0328 \\
(0.0242)\end{array}$ \\
\hline 1 if $\mathrm{HH}$ had non-agricultural business & & & $\begin{array}{c}0.0413 \\
(0.0399)\end{array}$ & $\begin{array}{l}0.0404 \\
(0.046)\end{array}$ & $\begin{array}{c}0.0995 \\
(0.0705)\end{array}$ \\
\hline Observations & 838 & 838 & 767 & 767 & 767 \\
\hline $\begin{array}{l}\text { R-squared } \\
\text { Year dummy }\end{array}$ & 0.0109 & $\begin{array}{c}0.0196 \\
\text { Yes }\end{array}$ & 0.38 & 0.527 & 0.629 \\
\hline Year $\times$ district & & & Yes & Yes & Yes \\
\hline Parish Fixed Effects & & & & Yes & \\
\hline Mother Fixed Effects & & & & & Yes \\
\hline
\end{tabular}

(1) Standard errors are clustered at the district level. Significance level: ${ }^{*} p<0.1,{ }^{* *} p<0.05,{ }^{* * *} p<0.01$. (2) In addition to the control variables listed, the regressions (3)-(5) control for a dummy, indicating that the distance from the household to the closest road was larger than the mean, a dummy indicating that the distance from the household to the reference point of the village was larger than the mean, a dummy indicating an area largely occupied by water surface, a dummy indicating that the distance from the household location to the reference point of the village was larger than the mean, a dummy indicating that the driving time to the nearest district town from the village was less than the mean, three dummies for the number of higher-level health facilities, and two dummies for the number of lower-level health facilities.

\subsection{Mobile Money Impact on Take-Up of Delivery Care}

Table 4 presents the regression results of the specifications to examine the mobile money adoption effect on the facility delivery dummy and the SBA dummy (control variables are not shown for brevity). Columns 1 and 5 report the OLS results with year dummies. While those specifications show significant estimates of the coefficient of interest, when we control for district-by-time dummies, the results come out to be not significant (columns 2 and 6). Even after controlling parish-fixed effects or mother-fixed effects, the estimates of the coefficient of interest are not significant (columns 3, 4, 7, and 8). We test the robustness of the results by using two other delivery-related variables: a dummy which is one if a mother and a baby took postnatal care within 40 days after birth and a dummy which is one if a baby's weight was measured right after the birth. The results on both variables do not show significant estimates (not shown for brevity). 
Table 4. Delivery-related outcome variables.

\begin{tabular}{|c|c|c|c|c|c|c|c|c|}
\hline & \multicolumn{4}{|c|}{ Facility Delivery } & \multicolumn{4}{|c|}{ SBA } \\
\hline & (1) & (2) & (3) & (4) & (5) & (6) & (7) & (8) \\
\hline \multicolumn{9}{|l|}{ Variables } \\
\hline 1 if $\mathrm{HH}$ used mobile money & $\begin{array}{l}0.192^{* * *} \\
(0.0474)\end{array}$ & $\begin{array}{c}0.0678 \\
(0.1)\end{array}$ & $\begin{array}{c}-0.00839 \\
(0.107)\end{array}$ & $\begin{array}{c}-0.0997 \\
(0.115)\end{array}$ & $\begin{array}{l}0.172 * * * \\
(0.0501)\end{array}$ & $\begin{array}{l}0.0519 \\
(0.106)\end{array}$ & $\begin{array}{c}-0.0000323 \\
(0.109)\end{array}$ & $\begin{array}{l}-0.0506 \\
(0.0843)\end{array}$ \\
\hline Observations & 1230 & 1099 & 1099 & 1099 & 1246 & 1115 & 1115 & 1115 \\
\hline R-squared & 0.0323 & 0.408 & 0.542 & 0.473 & 0.0329 & 0.406 & 0.546 & 0.479 \\
\hline Year dummy & Yes & & & & Yes & & & \\
\hline Year $\times$ district & & Yes & Yes & Yes & & Yes & Yes & Yes \\
\hline Parish Fixed Effects & & & Yes & & & & Yes & \\
\hline Mother Fixed Effects & & & & Yes & & & & Yes \\
\hline
\end{tabular}

(1) Standard errors are clustered at the district level. Significance level: ${ }^{* * *} p<0.01$. (2) The regressions (2)-(4) and (6)-(8) control for the age of the mother, the years of education of the mother, the years of education of the household head, the number of parity, the number of the household members, the number of migrants in the household, $\log$ of the value of the asset owned by the household, log of the size of the land used by the household, a dummy indicating that the household had a mobile phone, a dummy indicating that the household had a non-agricultural business, a dummy indicating that the distance from the household to the closest road was larger than the mean, a dummy indicating that the distance from the household to the reference point of the village was larger than the mean, a dummy indicating an area largely occupied by water surface, a dummy indicating that the distance in altitude from the household location to the reference point of the village was more than the mean, a dummy indicating that the driving time to the nearest district town from the village was less than the mean, three dummies for the number of higher-level health facilities, and two dummies for the number of lower-level health facilities.

Those results do not support the existence of a positive mobile money impact on facility delivery and delivery with an SBA. However, we should take it with caution. Compared to the standard errors in the estimates of the mobile money effect for recommended ANC (0.04-0.05 in fixed effects models) in Table 3, the standard errors in the estimates of the mobile money effect for delivery-related variables in Table 4 are large (0.08-0.11 in fixed effects models).

In Figure 3, we graphically illustrate the estimated effects of mobile money adoption on recommended ANC, facility delivery, and SBA-this is essentially a summary of Tables 3 and 4 . We show estimates from community- and mother-fixed effects models. One can find that mobile money adoption has positive effects on improving access to ANC. One can also see that the results for delivery-related variables failed to reject the null hypothesis of no mobile money effect, though the standard errors are large. Mean values—including both mobile money users and nonusers—of each outcome variable of 2009-2015 are shown for reference.

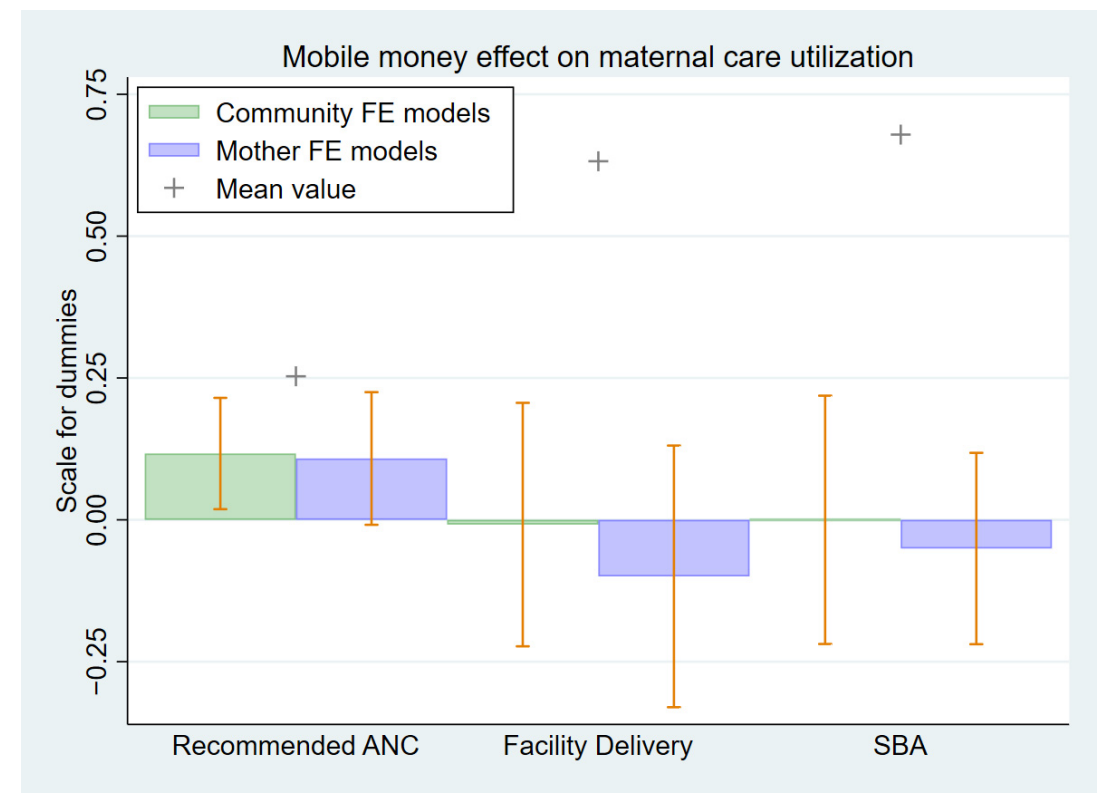

Figure 3. Effect of mobile money use on maternal care utilization. 


\subsection{Heterogeneity Analysis}

A heterogeneity analysis is useful because we can see what kind of people mobile money benefits more. We can also conjecture the mechanism through which mobile money supports the uptake of healthcare. This section investigates the heterogeneity in the impact of mobile money adoption on the take-up of ANC by two factors: (1) the distance from households' location to the closest main road and (2) the initial availability of higher-level health facilities of villages. Theoretically, mobile money may or may not bring a more substantial benefit to a geographically challenged household. Mobile money may give broader options of the mode of transport to a geographically challenged household; thus, such a household may respond more to the adoption of mobile money. On the contrary, by solving the problem of the high out-of-pocket health costs, mobile money may bring more benefit to an expectant mother who has better access to health facilities. To study the issue, we firstly employed a dummy variable that takes a value of one if a household is located more than 1.3 miles (mean) away from the closest main road. We secondly used a dummy variable that takes a value of one if a household is located in a village which initially had at least one higher-level health facility within 5 miles in 2008 . The reference year of the time-invariant dummy variable is set to 2008 because mobile money became available in Uganda in 2009.

More specifically, in this section, we test the following two hypotheses (though whether mobile money brings a larger benefit to a geographically challenged household is unclear before we run regressions).

Hypothesis $4 \mathbf{~ ( H 4 ) . ~ T h e ~ p o s i t i v e ~ e f f e c t ~ o f ~ m o b i l e ~ m o n e y ~ a d o p t i o n ~ o n ~ a n t e n a t a l ~ c a r e - s e e k i n g ~ b e h a v i o r ~ i s ~ s t r o n g e r ~}$ for households located far from the closest main road.

Hypothesis 5 (H5). The positive effect of mobile money adoption on antenatal care-seeking behavior is stronger for households who lived in villages that did not initially have a WHO-recommended level (higher-level) health facility around their residential area.

The results consistently indicate that mobile money brings a larger benefit to a geographically challenged household. In Table 5, we present the results of the parish- and mother-level fixed effects models, which include the interaction terms of the two factors. The results in panel (a) indicate that the impact of mobile money adoption is greater for women whose houses are far from the closest main road. Amongst such women, the take-up rate of recommended ANC increases by 22.8 (parish-fixed effects model) or 26.0 (mother-fixed effects model) percent points for the households which adopted mobile money. The estimate of the coefficient of the interaction term is significant at the five percent level in the mother-fixed effects model. The estimate of the interaction term in the parish-fixed effects model is also positive, while it is marginally significant.

The results in panel (b) indicate that the impact of mobile money adoption is greater for women whose houses are located in a village that did not initially have a higher-level health facility within 5 miles. Amongst such women, the take-up rate of recommended ANC increases by 37.7 (parish-fixed effects model) or 26.3 (mother-fixed effects model) percent points for the household which adopted mobile money. We test the robustness of the results by using dummy variables indicating the existence of health facilities within 3 miles instead of 5 miles; the results did not change qualitatively. 
Table 5. Heterogeneity in the impact of adoption of mobile money.

(a) Interaction variable: household is far from the closest main road

Outcome variable: 1 if mother received recommended ANC (4 times, 1-1-2).

\begin{tabular}{ccc} 
Variables & & \\
\hline 1 if HH used mobile money & 0.0524 & -0.0257 \\
& $(0.0588)$ & $(0.089)$ \\
Interacting variable (far from main road) & 0.175 & $0.286^{* *}$ \\
& $(0.104)$ & $(0.11)$ \\
1 if HH was far from closest road & 0.0507 & \\
Observations & $(0.125)$ & \\
R-squared & 767 & 767 \\
Year $\times$ district & 0.525 & 0.632 \\
Parish Fixed Effects & Yes & Yes \\
Mother Fixed Effects & Yes & \\
Effect of mobile money on HH locating far from main road & $0.228^{* *}$ & $0.26^{* * *}$ \\
& $(0.09)$ & $(0.06)$ \\
\hline
\end{tabular}

(b) Interaction variable: initial health facility condition of village

Outcome variable: 1 if mother received recommended ANC (4 times, 1-1-2).

Variables

\begin{tabular}{|c|c|c|}
\hline 1 if $\mathrm{HH}$ used mobile money & $\begin{array}{l}0.377^{* * *} \\
(0.0635)\end{array}$ & $\begin{array}{l}0.263 \text { *** } \\
(0.0649)\end{array}$ \\
\hline Interacting variable (initial health facility condition) & $\begin{array}{c}-0.345^{* * *} \\
(0.0667)\end{array}$ & $\begin{array}{c}-0.24 * * \\
(0.115)\end{array}$ \\
\hline 1 indicating existence of any higher-level health facilities in 2008 ( $\leq 5$ miles) & $\begin{array}{c}0.131 \\
(0.208)\end{array}$ & \\
\hline Observations & 767 & 767 \\
\hline R-squared & 0.53 & 0.627 \\
\hline Year $\times$ district & Yes & Yes \\
\hline Parish Fixed Effects & Yes & \\
\hline Mother Fixed Effects & & Yes \\
\hline
\end{tabular}

(1) Standard errors are clustered at the district level. Significance level: ${ }^{* *} p<0.05, * * * p<0.01$. (2) The regressions control for the age of the mother, the years of education of the mother, the years of education of the household head, the number of parity, the number of the household members, the number of migrants in the household, log of the value of the asset owned by the household, log of the size of the land used by the household, a dummy indicating that the household had a mobile phone, a dummy indicating that the household had a non-agricultural business, a dummy indicating that the distance from the household to the closest road was larger than the mean, a dummy indicating that the distance from the household to the reference point of the village was larger than the mean, a dummy indicating an area largely occupied by water surface, a dummy indicating that the distance in altitude from the household location to the reference point of the village was more than the mean, a dummy indicating that driving time to the nearest district town from the village was less than the mean, a dummy which takes a value of one indicating the existence of any higher-level health facilities, and a dummy which takes a value of one indicating the existence of any lower-level health facilities.

Figure 4 graphically presents the heterogeneous effects of mobile money use on the uptake of recommended ANC. The key estimates of Table 5 panel (a) are shown over the label "HHs living far from roads;" those of panel (b) are shown over the label "HHs of areas with few hospitals"-labels are simplified. The estimates illustrate that mobile money brings larger benefits to geographically challenged households. For reference, over the label "All HHs (Households)," we show the mean effects (the same to estimates shown in Figure 3) and the mean value of uptake of recommended ANC. 


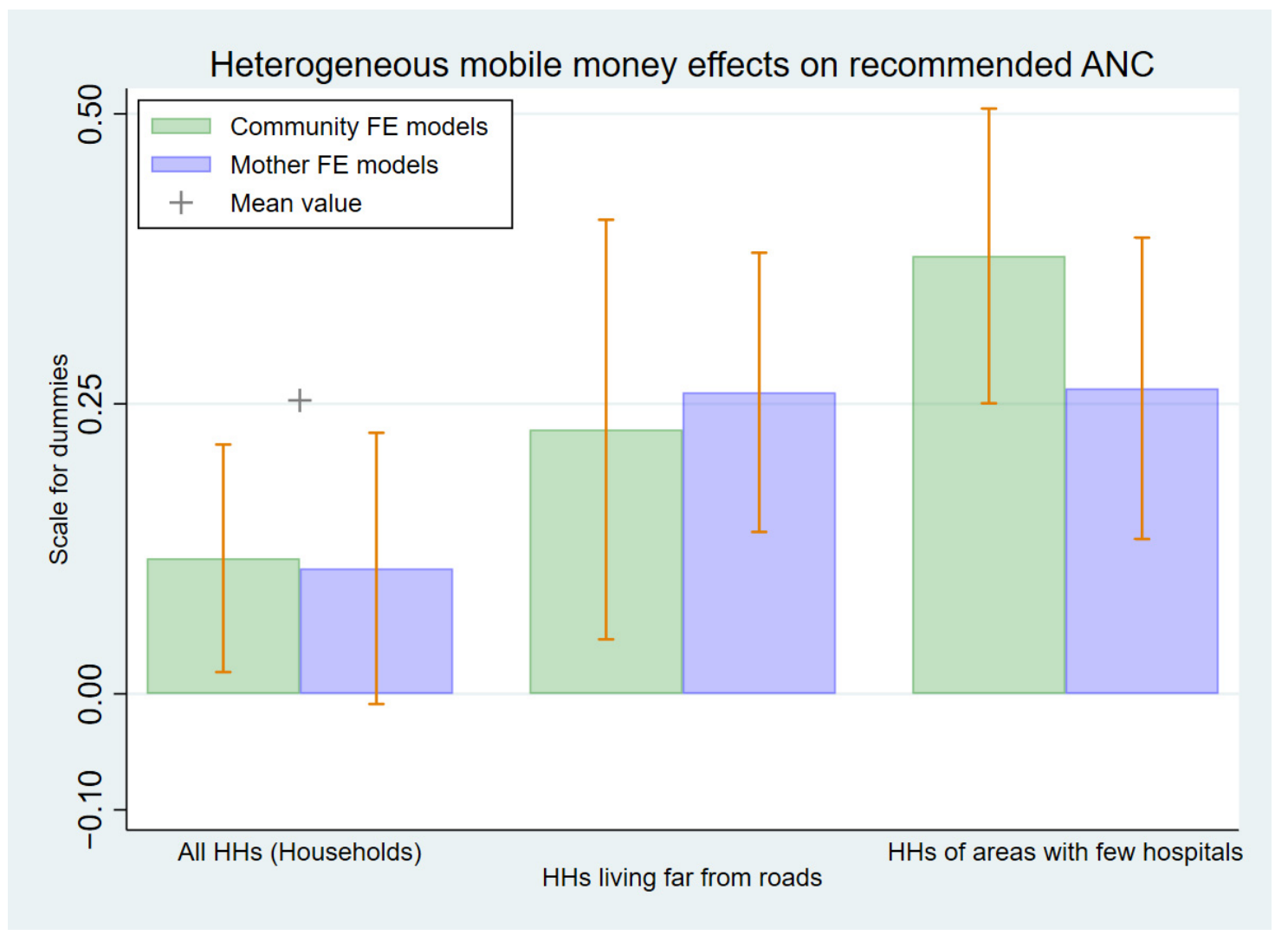

Figure 4. Heterogeneous effects of mobile money use on receiving recommended ANC.

\subsection{Falsification Tests}

One may imagine that the mobile money users and nonusers were systematically different and that the "mobile money adoption effect" shown above could be explained by the observed/unobserved characteristics which could have existed even in the absence of mobile money. To answer the concern of violating the common trend assumption, we run regressions for the recommended ANC dummy used above on a placebo mobile money dummy. In this estimation, we use a subset of observations which are from 2006 to 2009 . We restricted the data to this period because the mobile money service began in March 2009. At the beginning of the business, there were few users in a rural area. The placebo mobile money dummy takes a value of one in 2008 and 2009 for the people who used mobile money in 2015; it takes a value of zero for the rest of the observations in the subset. For example, if a household started to use mobile money in 2015, the placebo mobile money dummy takes a value of one in 2008 and 2009. For the outcome variable-the recommended ANC—we do not make any changes.

The results are shown in Table 6. The coefficients of the placebo dummy are consistently shown insignificant and almost zero. The results indicate that the outcome variable was not significantly different between mobile money users and nonusers before the penetration of the mobile money service. We also conducted another falsification test by using a different placebo dummy (the dependent variable is the same: recommended ANC); the results are consistent (see Table A5 in Appendix F). 
Table 6. Falsification test: placebo mobile money dummy (2006 2009).

\begin{tabular}{cccccc}
\hline \multicolumn{6}{c}{ Outcome Variable: 1 If Mother Received Recommended ANC (4 Times, 1-1-2). } \\
\hline & $\mathbf{( 1 )}$ & $\mathbf{( 2 )}$ & $\mathbf{( 3 )}$ & $\mathbf{( 4 )}$ & $\mathbf{( 5 )}$ \\
\hline Variables & \multicolumn{7}{c}{} \\
\hline Placebo mobile money dummy & -0.0026 & 0.00121 & -0.0223 & -0.0202 & 0.0401 \\
& $(0.0438)$ & $(0.059)$ & $(0.0723)$ & $(0.105)$ & $(0.0535)$ \\
Observations & 490 & 490 & 441 & 441 & 441 \\
R-squared & 0.00001 & 0.00778 & 0.318 & 0.509 & 0.39 \\
Year dummy & & Yes & Yes & Yes & Yes \\
Year $\times$ district & & & & Yes & Yes \\
Parish Fixed Effects & & & & &
\end{tabular}

(1) Standard errors are clustered at the district level. (2) The regressions (3)-(5) control for the age of the mother, the years of education of the mother, the years of education of the household head, the number of parity, the number of the household members, the number of migrants in the household, log of the value of the asset owned by the household, log of the size of the land used by the household, a dummy indicating that the household had a mobile phone, a dummy indicating that the household had a non-agricultural business, a dummy indicating that the distance from the household to the closest road was larger than the mean, a dummy indicating that the distance from the household to the reference point of the village was larger than the mean, a dummy indicating an area largely occupied by water surface, a dummy indicating that the distance in altitude from the household location to the reference point of the village was more than the mean, a dummy indicating that the driving time to the nearest district town from the village was less than the mean, three dummies for the number of higher-level health facilities, and two dummies for the number of lower-level health facilities. (3) The placebo mobile money dummy takes a value of one in 2008 and 2009 for the households which used mobile money in 2015; it takes a value of zero for the rest of the observations in the subset.

\subsection{Robustness Checks}

As robustness checks, in addition to the outcome variable of taking recommended ANC, we run regressions for two more outcome variables of ANC. Those are a dummy indicating take-up of five times of ANC (which also needs to satisfy the requirement of recommended ANC) and the number of times for which a mother took ANC (Table 7). The regression results of the dummy indicating take-up of five times of ANC show that the magnitude of mobile money adoption effect on ANC is similar to our primary outcome variable (recommended ANC). Further, the regression results of the number of times of ANC also suggest that there is a positive effect of mobile money adoption. However, those interpretations of the regression results need to be taken with caution because the estimates of mother-fixed effects models are not significant. This would probably stem from the nature of the two outcome variables: the dummy for ANC of five times and the number of ANC. The recommendation of WHO requires four routine ANC visits. If a mother does not face any problems such as pregnancy complications, she is not recommended-by doctors or the staff of health centers-to have more than four ANC visits. Thus, whether a mother has more than four visits strongly depends on whether complications occur. When a mother faces complications during pregnancy, she will receive more ANC whether or not she uses mobile money. In such cases, compared to estimates for recommended ANC, due to additional errors caused by problems during pregnancies, it would be more difficult to obtain significant estimates for the dummy of ANC five times and the number of ANC. This might be a reason that the estimates of mother-fixed effects models are not significant in the robustness checks. Nonetheless, the results of village-fixed effects models indicate positive and significant mobile money effects; the estimates of mother-fixed effects models show the expected sign-positive-with reasonable magnitudes. Overall, these results support the existence of positive mobile money effects on the uptake of ANC, though they are not conclusive. 
Table 7. Robustness checks.

(a) Outcome variable: 1 if mother received ANC five times, holding at least 1-1-2 times for each trimester

\begin{tabular}{|c|c|c|c|c|}
\hline Variables & (1) & (2) & (3) & (4) \\
\hline 1 if $\mathrm{HH}$ used mobile money & $\begin{array}{l}0.0679 \\
(0.048)\end{array}$ & $\begin{array}{l}0.121 * * \\
(0.0585)\end{array}$ & $\begin{array}{l}0.105 * * \\
(0.0495)\end{array}$ & $\begin{array}{c}0.0517 \\
(0.0572)\end{array}$ \\
\hline Observations & 838 & 767 & 767 & 767 \\
\hline R-squared & 0.0105 & 0.358 & 0.52 & 0.62 \\
\hline Year dummy & Yes & & & \\
\hline Year $\times$ district & & Yes & Yes & Yes \\
\hline Parish Fixed Effects & & & Yes & \\
\hline Mother Fixed Effects & & & & Yes \\
\hline
\end{tabular}

(b) Outcome variable: number of times that mother received ANC

\begin{tabular}{ccccc}
\hline Variables & $\mathbf{( 1 )}$ & $\mathbf{( 2 )}$ & $\mathbf{( 3 )}$ & $\mathbf{( 4 )}$ \\
\hline 1 if HH used mobile money & $0.621^{*}$ & 0.414 & $0.667^{*}$ & 0.395 \\
Observations & $(0.317)$ & $(0.349)$ & $(0.339)$ & $(0.605)$ \\
R-squared & 833 & 762 & 762 & 762 \\
Year dummy & 0.0112 & 0.339 & 0.519 & 0.578 \\
Year $\times$ district & Yes & & & Yes \\
Parish Fixed Effects & & Yes & Yes & Yes \\
Mother Fixed Effects & & & & \\
\hline
\end{tabular}

(1) Standard errors are clustered at the district level. Significance level: ${ }^{*} p<0.1{ }^{* *} p<0.05$. (2) To mitigate the influence of outliers, the number of times that a mother received ANC is replaced with ten if the numbers exceed ten. (3) The regressions (2)-(4) control for the age of the mother, the years of education of the mother, the years of education of the household head, the number of parity, the number of the household members, the number of migrants in the household, log of the value of the asset owned by the household, log of the size of the land used by the household, a dummy indicating that the household had a mobile phone, a dummy indicating that the household had a non-agricultural business, a dummy indicating that the distance from the household to the closest road was larger than the mean, a dummy indicating that the distance from the household to the reference point of the village was larger than the mean, a dummy indicating an area largely occupied by water surface, a dummy indicating that the distance in altitude from the household location to the reference point of the village was more than the mean, a dummy indicating that the driving time to the nearest district town from the village was less than the mean, three dummies for the number of higher-level health facilities, and two dummies for the number of lower-level health facilities.

\section{Limitation}

In this section, we explain the limitations of this study. An important limitation is the potential endogeneity. Though we control for several primary observables at the mother, household, and village levels, we cannot rule out the potential bias which might be caused by unobservables. We also provide an explanation of the data limitation, which stems from the nature of the surveys that we use.

\subsection{Potential Endogeneity}

Our estimates could be biased by three potential sources of endogeneity. The first is the mother-level correlation between mobile money use and maternal care use. If a pregnant woman with specific characteristics is more likely to make health visits while her household is more likely to use mobile money, our estimates would be upwardly biased without controlling for such characteristics. The second is the household-level correlation. A pregnant woman of a household with specific characteristics which correlates with mobile money use might be more likely to make health visits. The third is the village-level correlation between mobile money agents' location and health facilities' location. If a mobile money agent is more likely to choose a place that has good access to health facilities, it would also bias our results.

To deal with the first and the second sources of endogeneity, we control for many observable characteristics. We can list a number of potential sources of endogeneity. Starting with mother-level 
endogeneity: a more educated woman could be more likely to use maternal care. At the same time, she might be more likely to belong to a mobile money user household.

Similarly, we can list several potential factors that cause household-level endogeneity. For example, mobile phone use of a household, which correlates with mobile money use, may positively affect the take-up of maternal care. Further, if the number of household members is large, the probability of using mobile money could be high, while the household members could also help a pregnant woman make health visits. If a household sends migrant workers to towns, the household has a higher probability of using mobile money, while remittances from the migrant workers give more abundant options of maternal care to a pregnant woman. Moreover, a relatively wealthy household is more likely to use mobile money, while a woman in such a household could be more likely to take up maternal care. The location of a household might also correlate with mobile money use. For example, a household which is located closer to the center of the village might be more likely to use mobile money. Similarly, if a household is located closer to the main road, it might also affect the take-up of mobile money. In our regressions, we control for all the observable characteristics listed above. In addition to those, we control for any unobservable time-invariant characteristics that might correlate with mobile money use by mother-fixed effects.

We also use several village-level characteristics to control for endogeneity. Firstly, as a time-variant variable, we control for the number of health facilities around a village. If an agent chooses a place to attract more customers, the location might correlate with the location of health facilities. That causes an upward bias in our results. Secondly, as a time-invariant variable, we control for the road condition from a village to the nearest district town. This factor could be related to the location of an agent because an agent may prefer to stay at a place that has good access to a district town. In addition to those, any unobservable time-invariant characteristics such as culture or social norm, which might affect both mobile money use and take-up of maternal care, are controlled by parish-fixed effects.

Besides, we control for time-variant unobservables at the district level by using district-by-time dummies. However, we cannot rule out endogeneity caused by time-variant unobservables at a more granular level. There are several possible unobservables. Unfortunately, we do not have the data on household characteristics between the survey rounds. For example, between 2009 and 2012 or 2012 and 2015, a household might have extra earnings, sent migrants, or experienced change in their business. Such an event might correlate with mobile money use and maternal care.

One additional concern is reverse causality or simultaneity; it might be the case that a household starts to use mobile money to receive money to pay for maternal care services. However, in our context, the size of the endogeneity threat by reverse causality would be relatively small because only $10.8 \%$ of the mobile money users answered that their purpose for using mobile money is for paying medical costs (shown in Figure A1 in Appendix E). Thus, compared to the studies analyzing mobile money effects on total consumption or educational investment-those are the primary purposes of using mobile money-the concern of reverse causality is thought to be less serious. On top of that, we utilize lagged mobile money users' indicators to supplement our argument on reverse causality. In economics and finance, lagging explanatory variables are often used for mitigating reverse causality problems [44]. The estimated results of the mother-fixed effects model are shown in Appendix F (Table A7). The magnitude of the estimate of mobile money effects on ANC is close to that of the main regression, and the sign is positive. However, the estimate is not statistically significant. Due to the nature of our dataset, we see the large standard errors. The data we use is an unbalanced panel; by lagging mobile money users' indicators, we changed a large portion of mobile money users' observations to mobile money nonusers. This change would lead to large standard errors in the estimates and hence insignificant results. From this analysis, we could not rule out possible biases due to reverse causality, but at least the results do not contradict our claim.

To control for endogeneity, in the previous studies, including some using the RePEAT data $[4,7,8]$, the IV estimates are used. Those studies use the location of agents as their instrumental 
variables. Such a strategy can address the household-level endogeneity, though it cannot avoid the village-level endogeneity.

In this study, we also tried an instrumental variable approach. However, we find it challenging to use the location of agents as an instrumental variable in our case. We have data on the location of agents only in 2012 and 2015. Meanwhile, this study uses annual data on the use of maternal care. Unfortunately, we find that agents' information in 2012 and 2015 is too weak to explain the annual level variation of mobile money use as an instrumental variable. Overall, we control for several primary observables at the mother level, at the household level, and at the village level, but we cannot rule out endogeneity, which would be a limitation of our study.

\subsection{Data Limitation}

After being shown that mobile money adoption motivates maternal health-seeking behavior, one may want to know about the improvement of maternal and infant health outcomes. Due to the data limitation, we cannot show evidence on positive mobile money effects on such health outcomes. The RePEAT surveys have a limited number of health-related questions because the surveys were not originally designed for collecting health data-the surveys mainly focus on rural agriculture. Also, though the surveys have questionnaires on a few aspects of maternal and infant health outcomes such as pregnancy complications or birth weight, the number of missing values of the answers to those questions is large and the sample size is likely to be too small—recall errors add to it—to find a robust and meaningful effect of mobile money use. Therefore, this study focuses on the effect of mobile money adoption on maternal care utilization. However, focusing on maternity care utilization and not maternal and infant health outcomes is found in many articles. For example, a systematic review of the effects of cash transfers and vouchers on the use of maternal care which uses data from 51 studies concludes that there are few studies to estimate maternal and infant health outcomes [45].

\section{Discussion}

Existing studies find that financial inclusion tools positively affect the users' take-up of healthcare. In this study, we find suggestive evidence that the adoption of mobile money, which is another tool of financial inclusion, encourages women to make the WHO-recommended four ANC visits. We confirm the robustness of our results by using several other ANC-related variables as outcome variables. The results of placebo tests, which consist of observations before the introduction of mobile money, also support that finding. However, it is worth noting that the results should be interpreted with caution since we cannot completely rule out possible biases due to endogeneity. Heterogeneity analysis indicates that mobile money use brings a greater benefit to geographically challenged households, such as those located far from the main road or with a fewer health facilities nearby, than those that are not. These results suggest that mobile money use supports rural women to visit distant health facilities to receive ANC. In contrast, no evidence is found of a statistically significant impact of mobile money use on the take-up of facility delivery and delivery with an SBA.

The results suggest that the magnitude of mobile money's positive impact on the uptake of recommended ANC is around ten percentage points, while the attendance rate of recommended ANC in 2009 in rural Uganda (not shown) was 23.8 percent. It is not easy to compare the magnitude of the impacts between different contexts, mainly because the baseline take-up rates of maternal care are different. In rural Ugandan context (period 2001-2012), Manang and Yamauchi [21] find that the establishment of a new clinic increased the take-up of ANC by 19 percentage points. Although clinics typically do not provide ANC, their establishment enhances the ANC take-up among expectant women nearby, possibly because clinics give information on health facilities providing ANC in their neighborhood. In our study, the estimated magnitude of the impact of mobile money use on recommended ANC is modest relative to the effect of the establishment of a new clinic in Uganda. Besides, a recent systematic review on giving incentives to encourage maternal care use [45] finds that the effect of conditional cash transfers on uptake of ANC is a ten-percentage-point increase. 
We find a positive correlation of mobile money usage with ANC but do not find such a correlation with delivery-related variables. This is not surprising because it is common to find that a tool is useful for supporting the uptake of a specific type of maternal care and, at the same time, that the tool is not useful for encouraging the take-up of another type of maternal care. For example, a systematic review by Hunter et al. [45] studies what kind of maternity care (for example, ANC or SBA) can be effectively encouraged by what type of policy interventions (for example, conditional cash transfers or vouchers). One of their findings is that conditional cash transfer has a strong positive effect on uptake of ANC while having a weaker effect on birth with an SBA. In our context, we can conjecture several reasons why a positive mobile money effect is found for ANC but not for delivery-related variables. Firstly, the facility delivery and SBA delivery rates are already high in the sample-the rates (not shown) in 2009 are 57.2 percent for facility delivery and 64.9 percent for delivery with an SBA. Secondly, the difference in the timing between delivery care and ANC might be the reason. Multiple ANC contacts require a mother to have cash in her hands regularly. Mobile money could have brought cash to her hands. Meanwhile, delivery requires a large amount of money at only a specific period. One can also approximately expect when the delivery happens. Thus, if a household recognizes that the payment for delivery is a necessary cost and prepares it in advance, mobile money may play a limited role.

We can compare our findings to those in a limited number of studies on the impact of mobile money adoption on health. Mathieu and Kakinaka's recent work, which uses cross-sectional data of Burkina Faso and applies matching methods, uses a qualitative measure of lack of healthcare as one of its outcome variables: stayed without medical treatment or medicine because you did not have money (1 Never 2 Rarely 3 Sometimes 4 Often). They conclude that adoption of mobile money improves the household's welfare status related to healthcare. An NBER (National Bureau of Economic Research) working paper investigates the relationship between mobile money usage and health-seeking behavior responding to adverse health shocks [46]. The study utilizes a panel data of Kenya and applies the difference-in-difference fixed effects model to the data. The study shows that mobile money usage helps households increase visits to health facilities responding to health shocks in general. Therefore, the findings of both studies are in line with our finding-adoption of mobile money improves access to healthcare.

Author Contributions: Conceptualization, H.E.; formal analysis, H.E. and T.M.; investigation, H.E.; methodology, H.E. and T.M.; project administration, H.E.; supervision, T.M.; writing—original draft, H.E.; writing-review and editing, T.M. All authors have read and agreed to the published version of the manuscript.

Funding: This research was funded by Yamada Gakujutsu Shorei Kikin, Zaisei Kinyu Kinyuhosei Kenkyu Kikin, JSPS KAKENHI grant number JP15H02619 and JSPS KAKENHI grant number JP18H00838.

Acknowledgments: We are thankful to Stephan Litschig, Joshua Angrist, Hideki Hashimoto, Rayner Tabetando, Keiko Ono, and participants at the workshop of Joshua Angrist hosted by The Center for Research and Education in Program Evaluation and to the Japanese Journal of Health Economics and Policy 11th Annual Meeting for their insightful comments and suggestions on earlier drafts of this paper. We thank Chihiro Egami and Masayuki Egami for providing superb research assistance. All errors are our own.

Conflicts of Interest: The authors declare no conflict of interest. The funders had no role in the design of the study; in the collection, analyses, or interpretation of data; in the writing of the manuscript; or in the decision to publish the results.

\section{Appendix A}

In this Appendix A, we elaborate on the surveys that we used.

\section{Appendix A.1. Household-Level Panel Survey}

- The RePEAT data of 2003-2012 consists of around 940 rural households.

- At the round for 2015, additional households were surveyed; 1732 households were surveyed in total. Among the households, 847 households were the households that were surveyed in 2012. The rest of the households were new samples. One hundred seventeen villages were sampled 
at the round for 2015 (meaning that 23 new villages were sampled); fifteen households were surveyed from each of the villages (meaning that five additional households were sampled from the 94 villages which were surveyed at the round for 2012; fifteen households were sampled from the 23 newly sampled villages). However, the questions on the maternal health-seeking behavior were not asked for the newly sampled 846 households. Thus, we do not include those additional households.

\section{Appendix A.2. Retrospective Reports on Maternity Care}

- The survey rounds for 2012 and 2015 asked retrospective questions on maternal care that we used.

- In the survey round for 2005, though mothers were asked about their pregnancy experiences, the questionnaire did not include questions on ANC. That is one of the reasons that we do not use pregnancy reports from round 2005.

\section{Appendix A.3. Retrospective Reports on Mobile Money Use}

- The survey rounds for 2012 and 2015 asked retrospective questions on mobile money use.

- $\quad$ The 2012 survey asked the following questions:

$\bigcirc \quad$ Do you/your spouse use mobile money services?

$\bigcirc \quad$ If yes, do you/your spouse own a mobile money account?

If yes, when did you open the account (year)?

- $\quad$ The 2015 survey asked the following questions:

Has any member of this household ever used mobile money?

$\bigcirc \quad$ If yes, which year did the first person start to use mobile money in this household?

- A drawback of using those questions to define mobile money use is measurement errors. The questions asked in which year a household opened a mobile money account (2012) or started to use mobile money (2015). Thus, we cannot know whether the household continued using mobile money frequently since then. A household might have stopped using mobile money. This causes measurement errors of the indicator of mobile money use. As a result, our estimate may have a downward bias and may be more conservative.

\section{Appendix B}

We implement interpolation of household-level data in the following manner. The values of the three survey rounds $(2009,2012$, and 2015) are copied to the years of pregnancy surrounding each survey round.

Table A1. Details of interpolation.

\begin{tabular}{ccc}
\hline Years of Pregnancy & Survey Years of the Data Used for Interpolation & \\
\hline 2007 & 2009 & Copied \\
2008 & 2009 & Copied \\
2009 & 2009 & Survey year \\
2010 & 2009 & Copied \\
2011 & 2012 & Copied \\
2012 & 2012 & Survey year \\
2013 & 2012 & Copied \\
2014 & 2015 & Copied \\
2015 & 2015 & Survey year \\
\hline
\end{tabular}




\section{Appendix C}

Appendix C.1. Questionnaire That Was Used for Constructing Outcome Variables

Appendix C.1.1. Recommended ANC

The questionnaire of the survey is "where did you typically receive antenatal care?" The RePEAT survey does not ask mothers where they receive ANC for each trimester. Thus, if a woman visited two or more types of providers, a typical provider was reported.

Appendix C.1.2. Facility Delivery

The questionnaire of the survey is "where did you go for delivery or for treatment for miscarriage?"

Appendix C.1.3. Skilled Birth Attendance

The questionnaire of the survey is "who attended the delivery?"

\section{Appendix C.2. How We Construct Dummy Indicating Road Condition}

- The dummy indicating road condition is time invariant. To create this variable, we mainly use the information in the round for 2015 because it covers the most significant number of villages. Three villages' information were complemented with the data of the 2012 round.

\section{Appendix D}

Table A2. Summary statistics by mobile money adoption status.

\begin{tabular}{|c|c|c|c|c|c|c|}
\hline & \multicolumn{3}{|c|}{ Mobile Money Nonuser } & \multicolumn{3}{|c|}{ Mobile Money User } \\
\hline & $\mathbf{N}$ & Mean & SD & $\mathbf{N}$ & Mean & SD \\
\hline \multicolumn{7}{|c|}{ Mother level characteristics } \\
\hline Age & 400 & 32.5 & 8.4 & 110 & 34.7 & 7.08 \\
\hline Education & 400 & 5.09 & 3.44 & 110 & 6.05 & 3.64 \\
\hline 1 if she is household head & 400 & 0.0775 & 0.268 & 110 & 0.0727 & 0.261 \\
\hline Number of pregnancies & 400 & 2.92 & 1.54 & 110 & 3.44 & 1.62 \\
\hline \multicolumn{7}{|c|}{ Household (HH) level characteristics } \\
\hline Head education & 352 & 5.86 & 3.66 & 101 & 7 & 3.94 \\
\hline Total value of assets (Ush) & 354 & 922,781 & $5,240,806$ & 103 & $1,294,126$ & $2,050,289$ \\
\hline Land holding size (acre) & 356 & 3.29 & 9.05 & 103 & 6.27 & 14 \\
\hline 1 if having non-agriculture business & 357 & 0.499 & 0.501 & 103 & 0.689 & 0.465 \\
\hline Number of HH members & 357 & 11 & 5.01 & 103 & 12.1 & 4.52 \\
\hline Number of migrants sent from $\mathrm{HH}$ & 357 & 0.336 & 1.11 & 103 & 0.35 & 0.871 \\
\hline 1 if mobile phone owned & 354 & 0.675 & 0.469 & 103 & 0.951 & 0.216 \\
\hline 1 if holds mobile money account & 374 & 0 & 0 & 106 & 1 & 0 \\
\hline 1 if holds bank account & 336 & 0.208 & 0.407 & 104 & 0.279 & 0.451 \\
\hline \multicolumn{7}{|c|}{ Village level characteristics } \\
\hline Number of higher-level health facilities around village ( $\leq 5 \mathrm{miles})$ & 89 & 1.48 & 1.08 & 66 & 1.55 & 1.07 \\
\hline Number of higher-level health facilities * around village ( $\leq 5 \mathrm{miles})$ & 89 & 1.56 & 1.19 & 66 & 1.71 & 1.24 \\
\hline Number of lower-level health facilities around village ( $\leq 5 \mathrm{miles})$ & 89 & 0.517 & 0.624 & 66 & 0.561 & 0.636 \\
\hline \multicolumn{7}{|c|}{ Pregnancy-level information } \\
\hline Year of pregnancy termination & 710 & 2010 & 2.03 & 134 & 2013 & 1.58 \\
\hline \multicolumn{7}{|c|}{ Antenatal care (ANC)-related information } \\
\hline Number of ANC visits & 703 & 4.71 & 2.94 & 130 & 4.88 & 2.86 \\
\hline Number of ANC visits at a higher-level health facility & 703 & 3.81 & 3.27 & 130 & 4.36 & 3.22 \\
\hline 1 if received recommended ANC ( 4 times, $1-1-2$, at a higher-level health facility) & 706 & 0.212 & 0.409 & 132 & 0.333 & 0.473 \\
\hline 1 if received ANC within first trimester at a higher-level health facility & 705 & 0.372 & 0.484 & 131 & 0.496 & 0.502 \\
\hline 1 if received ANC within second trimester at a higher-level health facility & 705 & 0.664 & 0.473 & 131 & 0.763 & 0.427 \\
\hline 1 if received ANC 2 times within third trimester at a higher-level health facility & 705 & 0.528 & 0.5 & 131 & 0.641 & 0.481 \\
\hline Cost of making an ANC visit (Ush) & 672 & 1983 & 8551 & 130 & 3791 & 9240 \\
\hline Transportation cost of making an ANC visit (Ush) & 623 & 1066 & 2081 & 123 & 1636 & 3329 \\
\hline Travel time for ANC & 673 & 48.3 & 45 & 130 & 37.4 & 33.7 \\
\hline Waiting time for ANC & 677 & 72.5 & 74.7 & 129 & 71.1 & 82.8 \\
\hline
\end{tabular}


Table A2. Cont.

\begin{tabular}{|c|c|c|c|c|c|c|}
\hline & \multicolumn{3}{|c|}{ Mobile Money Nonuser } & \multicolumn{3}{|c|}{ Mobile Money User } \\
\hline & $\mathbf{N}$ & Mean & SD & $\mathbf{N}$ & Mean & SD \\
\hline \multicolumn{7}{|c|}{ Delivery related information } \\
\hline Transportation cost for delivery (Ush) & 475 & 3498 & 7439 & 124 & 3299 & 9791 \\
\hline 1 if delivered by a skilled provider & 710 & 0.614 & 0.487 & 134 & 0.813 & 0.391 \\
\hline 1 if delivered at a higher-level health facility & 698 & 0.385 & 0.487 & 133 & 0.496 & 0.502 \\
\hline
\end{tabular}

Sources: The RePEAT study 2009/2012/2015. (1) According to the Bank of Uganda's Annual Report 2012, USD was equivalent to Uganda shilling 2557 in financial years 2011-12. (2) Age is calculated at the year of pregnancy terminated. We restrict the pregnancy reports to those of the past five years from the survey year. We also exclude the pregnancy reports answered by family members other than mothers themselves. (3) Higher-level health facilities with asterisks provide delivery care. Higher-level health facilities without asterisks provide comprehensive ANC. The RePEAT surveys collected the information in villages from informants. We use each of the variables to control for the regressions on corresponding outcome variables.

\section{Appendix E}

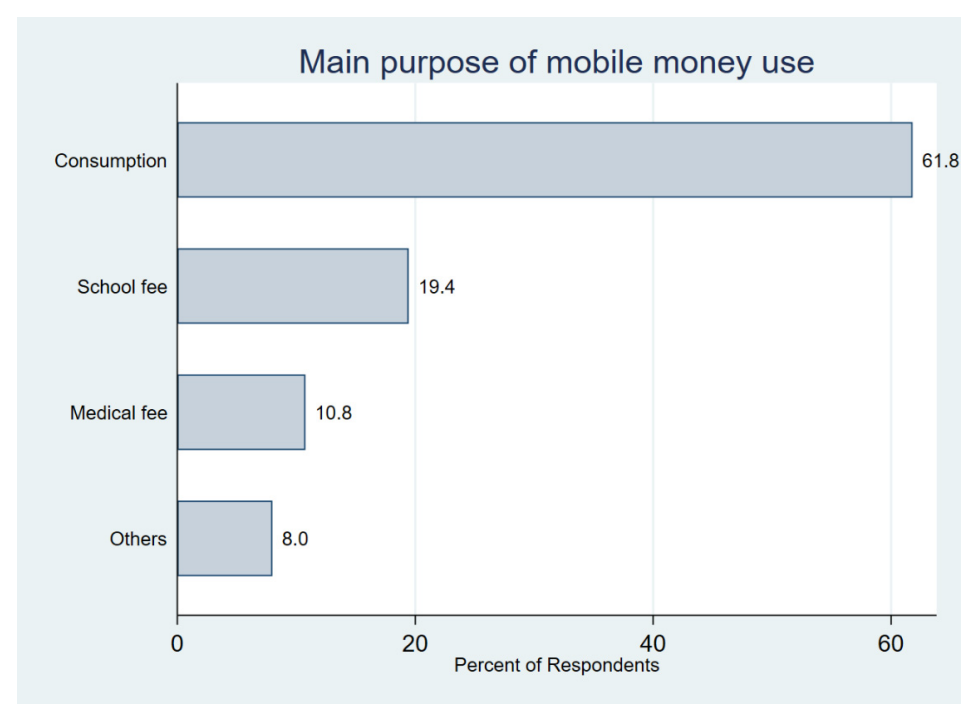

Figure A1. Purpose of mobile money use for receiving remittances. Source: RePEAT study 2015. 


\section{Appendix F}

Table A3. Recommended ANC (full sample).

Outcome Variable: 1 If Mother Received Recommended ANC (4 Times, 1-1-2).

\begin{tabular}{|c|c|c|c|c|c|}
\hline & (1) & (2) & (3) & (4) & (5) \\
\hline \multicolumn{6}{|l|}{ VARIABLES } \\
\hline 1 if $\mathrm{HH}$ used mobile money & $\begin{array}{l}0.146^{* * *} \\
(0.0363)\end{array}$ & $\begin{array}{l}0.127 * * * \\
(0.0409)\end{array}$ & $\begin{array}{c}0.0934 \\
(0.0637)\end{array}$ & $\begin{array}{c}0.076 \\
(0.0612)\end{array}$ & $\begin{array}{c}0.14 \\
(0.0912)\end{array}$ \\
\hline Years of education (mother) & & & $\begin{array}{l}-0.00442 \\
(0.00745)\end{array}$ & $\begin{array}{c}-0.00603 \\
(0.0102)\end{array}$ & \\
\hline Age (mother) & & & $\begin{array}{c}-0.000646 \\
(0.00223)\end{array}$ & $\begin{array}{c}0.0000997 \\
(0.00252)\end{array}$ & $\begin{array}{l}0.0251 \text { * } \\
(0.0127)\end{array}$ \\
\hline Parity & & & $\begin{array}{l}-0.0132 \\
(0.0135)\end{array}$ & $\begin{array}{c}-0.0151 \\
(0.015)\end{array}$ & $\begin{array}{c}0.0389 \\
(0.0432)\end{array}$ \\
\hline 1 if $\mathrm{HH}$ had mobile phone & & & $\begin{array}{l}0.00964 \\
(0.0479)\end{array}$ & $\begin{array}{c}0.0305 \\
(0.0519)\end{array}$ & $\begin{array}{c}0.0532 \\
(0.0749)\end{array}$ \\
\hline Number of $\mathrm{HH}$ members & & & $\begin{array}{c}0.0027 \\
(0.00309)\end{array}$ & $\begin{array}{c}0.00211 \\
(0.00344)\end{array}$ & $\begin{array}{c}0.000863 \\
(0.0221)\end{array}$ \\
\hline Number of migrants in $\mathrm{HH}$ & & & $\begin{array}{l}0.00423 \\
(0.0172)\end{array}$ & $\begin{array}{c}-0.000745 \\
(0.0147)\end{array}$ & $\begin{array}{c}-0.00836 \\
(0.023)\end{array}$ \\
\hline Asset value of $\mathrm{HH}(\log )$ & & & $\begin{array}{c}0.0104 \\
(0.0134)\end{array}$ & $\begin{array}{c}0.0088 \\
(0.0166)\end{array}$ & $\begin{array}{r}-0.0232 \\
(0.0168)\end{array}$ \\
\hline Land size of $\mathrm{HH}(\log )$ & & & $\begin{array}{c}-0.000746 \\
(0.00686)\end{array}$ & $\begin{array}{c}0.0000884 \\
(0.00801)\end{array}$ & $\begin{array}{l}-0.00365 \\
(0.00119)\end{array}$ \\
\hline $\mathrm{HH}$ head education (year) & & & $\begin{array}{c}0.00408 \\
(0.00632)\end{array}$ & $\begin{array}{c}0.00278 \\
(0.00701)\end{array}$ & $\begin{array}{c}-0.018 \\
(0.0163)\end{array}$ \\
\hline 1 if $\mathrm{HH}$ had non-agricultural business & & & $\begin{array}{c}0.0212 \\
(0.0394)\end{array}$ & $\begin{array}{l}0.00681 \\
(0.0406)\end{array}$ & $\begin{array}{c}0.0131 \\
(0.0667)\end{array}$ \\
\hline 1 if $\mathrm{HH}$ was far from closest road & & & $\begin{array}{l}0.0384 \\
(0.06)\end{array}$ & $\begin{array}{c}-0.00606 \\
(0.106)\end{array}$ & \\
\hline 1 if $\mathrm{HH}$ was far in altitude from village reference point & & & $\begin{array}{l}-0.0468 \\
(0.0726)\end{array}$ & $\begin{array}{c}-0.059 \\
(0.0959)\end{array}$ & \\
\hline Observations & 1633 & 1633 & 1468 & 1468 & 1468 \\
\hline R-squared & 0.0124 & 0.0233 & 0.313 & 0.415 & 0.421 \\
\hline Year dummy & & Yes & & & \\
\hline Year $\times$ district & & & Yes & Yes & Yes \\
\hline Parish FE & & & & Yes & \\
\hline Mother FE & & & & & Yes \\
\hline
\end{tabular}

(1) Standard errors are clustered at the district level. Significance level: ${ }^{*} p<0.1,{ }^{* * *} p<0.01$. (2) In addition to the control variables listed, the regressions (3)-(5) control for a dummy indicating an area largely occupied by water surface, a dummy indicating that the distance from the household location to the reference point of the village was larger than the mean, a dummy indicating that the driving time to the nearest district town from the village was less than the mean, three dummies for the number of higher-level health facilities, and two dummies for the number of lower-level health facilities. 
Table A4. Delivery-related outcome variables (full sample).

\begin{tabular}{|c|c|c|c|c|c|c|c|c|}
\hline & \multicolumn{4}{|c|}{ Facility Delivery } & \multicolumn{4}{|c|}{ SBA } \\
\hline & (1) & (2) & (3) & (4) & (5) & (6) & (7) & (8) \\
\hline \multicolumn{9}{|l|}{ VARIABLES } \\
\hline 1 if $\mathrm{HH}$ used mobile money & $\begin{array}{l}0.153 * * * \\
(0.0467)\end{array}$ & $\begin{array}{c}0.0277 \\
(0.0817)\end{array}$ & $\begin{array}{l}-0.0173 \\
(0.0919)\end{array}$ & $\begin{array}{c}0.00723 \\
(0.101)\end{array}$ & $\begin{array}{l}0.149^{* * *} \\
(0.0398)\end{array}$ & $\begin{array}{c}0.043 \\
(0.0682)\end{array}$ & $\begin{array}{c}-0.00353 \\
(0.0588)\end{array}$ & $\begin{array}{l}-0.0133 \\
(0.0566)\end{array}$ \\
\hline Years of education (mother) & & $\begin{array}{c}0.0068 \\
(0.00577)\end{array}$ & $\begin{array}{c}0.00616 \\
(0.00634)\end{array}$ & & & $\begin{array}{c}0.0116^{*} \\
(0.00654)\end{array}$ & $\begin{array}{c}0.0126^{*} \\
(0.007)\end{array}$ & \\
\hline Age (mother) & & $\begin{array}{c}-0.00409 * \\
(0.0022)\end{array}$ & $\begin{array}{c}-0.00286 \text { * } \\
(0.00167)\end{array}$ & $\begin{array}{l}0.00906 \\
(0.0138)\end{array}$ & & $\begin{array}{l}-0.0045^{*} \\
(0.00235)\end{array}$ & $\begin{array}{c}-0.0033 \\
(0.00227)\end{array}$ & $\begin{array}{c}0.0218 \\
(0.0136)\end{array}$ \\
\hline Parity & & $\begin{array}{c}-0.034 \\
(0.0224)\end{array}$ & $\begin{array}{c}-0.0352 * \\
(0.0205)\end{array}$ & $\begin{array}{l}0.0232 \\
(0.029)\end{array}$ & & $\begin{array}{c}-0.0254^{*} \\
(0.0149)\end{array}$ & $\begin{array}{l}-0.0193 \\
(0.0142)\end{array}$ & $\begin{array}{c}-0.00175 \\
(0.0297)\end{array}$ \\
\hline 1 if $\mathrm{HH}$ had mobile phone & & $\begin{array}{l}0.0597 \\
(0.065)\end{array}$ & $\begin{array}{c}0.0399 \\
(0.0729)\end{array}$ & $\begin{array}{c}0.124 \\
(0.0796)\end{array}$ & & $\begin{array}{c}0.0232 \\
(0.0534)\end{array}$ & $\begin{array}{c}-0.000309 \\
(0.0616)\end{array}$ & $\begin{array}{c}-0.095 \\
(0.0742)\end{array}$ \\
\hline Number of $\mathrm{HH}$ members & & $\begin{array}{c}0.0000116 \\
(0.00475)\end{array}$ & $\begin{array}{c}0.00175 \\
(0.00468)\end{array}$ & $\begin{array}{c}-0.00968 \\
(0.0107)\end{array}$ & & $\begin{array}{l}-0.00488 \\
(0.00367)\end{array}$ & $\begin{array}{c}-0.000747 \\
(0.00367)\end{array}$ & $\begin{array}{l}0.00237 \\
(0.0195)\end{array}$ \\
\hline Number of migrants in $\mathrm{HH}$ & & $\begin{array}{c}0.0076 \\
(0.0205)\end{array}$ & $\begin{array}{l}0.00926 \\
(0.0212)\end{array}$ & $\begin{array}{c}-0.018 \\
(0.0538)\end{array}$ & & $\begin{array}{c}0.023 \\
(0.0148)\end{array}$ & $\begin{array}{c}0.0152 \\
(0.0129)\end{array}$ & $\begin{array}{l}0.00356 \\
(0.0238)\end{array}$ \\
\hline Asset value of $\mathrm{HH}(\log )$ & & $\begin{array}{c}0.0546^{* *} \\
(0.0218)\end{array}$ & $\begin{array}{l}0.0634^{* *} \\
(0.0282)\end{array}$ & $\begin{array}{c}-0.00476 \\
(0.0206)\end{array}$ & & $\begin{array}{c}0.0582^{* * *} \\
(0.01411)\end{array}$ & $\begin{array}{c}0.0686^{* * *} \\
(0.0164)\end{array}$ & $\begin{array}{c}0.0431^{* * *} \\
(0.015)\end{array}$ \\
\hline Land size of $\mathrm{HH}(\log )$ & & $\begin{array}{c}0.00871 \\
(0.00764)\end{array}$ & $\begin{array}{c}0.00643 \\
(0.00911)\end{array}$ & $\begin{array}{c}-0.00712 \\
(0.0103)\end{array}$ & & $\begin{array}{c}0.00338 \\
(0.00667)\end{array}$ & $\begin{array}{c}0.00405 \\
(0.00763)\end{array}$ & $\begin{array}{c}-0.00498 \\
(0.0118)\end{array}$ \\
\hline HH Head Education (year) & & $\begin{array}{l}-0.00998 \\
(0.00631)\end{array}$ & $\begin{array}{l}-0.0113 * \\
(0.00566)\end{array}$ & $\begin{array}{c}-0.00315 \\
(0.013)\end{array}$ & & $\begin{array}{c}-0.00822 \\
(0.0058)\end{array}$ & $\begin{array}{c}-0.00951 \text { ** } \\
(0.0046)\end{array}$ & $\begin{array}{l}-0.0142 \\
(0.0121)\end{array}$ \\
\hline 1 if $\mathrm{HH}$ had non-agricultural business & & $\begin{array}{l}0.00848 \\
(0.0449)\end{array}$ & $\begin{array}{c}-0.00536 \\
(0.0492)\end{array}$ & $\begin{array}{c}-0.101 \\
(0.0682)\end{array}$ & & $\begin{array}{c}0.0172 \\
(0.0425)\end{array}$ & $\begin{array}{l}0.00733 \\
(0.0433)\end{array}$ & $\begin{array}{c}-0.059 \\
(0.0552)\end{array}$ \\
\hline 1 if $\mathrm{HH}$ was far from closest road & & $\begin{array}{l}-0.0591 \\
(0.0748)\end{array}$ & $\begin{array}{l}-0.163 \\
(0.118)\end{array}$ & & & $\begin{array}{l}-0.0186 \\
(0.0687)\end{array}$ & $\begin{array}{c}-0.208^{* *} \\
(0.0982)\end{array}$ & \\
\hline 1 if $\mathrm{HH}$ was far in altitude from village reference point & & $\begin{array}{l}-0.0706 \\
(0.0592)\end{array}$ & $\begin{array}{c}-0.03 \\
(0.0825)\end{array}$ & & & $\begin{array}{l}-0.0305 \\
(0.0653)\end{array}$ & $\begin{array}{c}0.0291 \\
(0.0988)\end{array}$ & \\
\hline Observations & 1649 & 1480 & 1480 & 1480 & 1683 & 1510 & 1510 & 1510 \\
\hline R-squared & 0.0238 & 0.375 & 0.491 & 0.413 & 0.0231 & 0.362 & 0.485 & 0.408 \\
\hline Year dummy & Yes & & & & Yes & & & \\
\hline Year $\times$ district & & Yes & Yes & Yes & & Yes & Yes & Yes \\
\hline $\begin{array}{l}\text { Parish FE } \\
\text { Mother FE }\end{array}$ & & & Yes & & & & Yes & Yes \\
\hline
\end{tabular}

(1) Standard errors are clustered at the district level. Significance level: ${ }^{*} p<0.1,{ }^{* *} p<0.05,{ }^{* * *} p<0.01$. (2) In addition to the control variables listed, the regressions (2)-(4) and (6)-(8) control for a dummy indicating an area largely occupied by water surface, a dummy indicating that the distance from the household location to the reference point of the village was larger than the mean, a dummy indicating that the driving time to the nearest district town from the village was less than the mean, three dummies for the number of higher-level health facilities, and two dummies for the number of lower-level health facilities. 
Table A5. Falsification test: another placebo mobile money dummy (2006-2009).

\begin{tabular}{|c|c|c|c|c|c|}
\hline \multicolumn{6}{|c|}{ Outcome Variable: 1 If Mother Received Recommended ANC (4 Times, 1-1-2). } \\
\hline & (1) & (2) & (3) & (4) & (5) \\
\hline \multicolumn{6}{|l|}{ VARIABLES } \\
\hline Placebo mobile money dummy & $\begin{array}{c}0.0442 \\
(0.0714)\end{array}$ & $\begin{array}{c}-0.00563 \\
(0.0959)\end{array}$ & $\begin{array}{c}-0.0563 \\
(0.124)\end{array}$ & $\begin{array}{c}-0.0837 \\
(0.136)\end{array}$ & $\begin{array}{c}-0.00258 \\
(0.0701)\end{array}$ \\
\hline Years of education (mother) & & & $\begin{array}{l}-0.0119 \\
(0.00897)\end{array}$ & $\begin{array}{l}-0.0145 \\
(0.0147)\end{array}$ & \\
\hline Age (mother) & & & $\begin{array}{l}-0.00389 \\
(0.00454)\end{array}$ & $\begin{array}{c}0.00199 \\
(0.00624)\end{array}$ & $\begin{array}{l}0.000323 \\
(0.00876)\end{array}$ \\
\hline Parity & & & $\begin{array}{c}-0.00919 \\
(0.036)\end{array}$ & $\begin{array}{c}0.0138 \\
(0.0429)\end{array}$ & $\begin{array}{l}0.0304 \\
(0.135)\end{array}$ \\
\hline 1 if $\mathrm{HH}$ had mobile phone & & & $\begin{array}{l}-0.147^{*} \\
(0.0736)\end{array}$ & $\begin{array}{l}-0.114 \\
(0.131)\end{array}$ & \\
\hline Number of HH members & & & $\begin{array}{l}-0.00784 \\
(0.00663)\end{array}$ & $\begin{array}{l}-0.00841 \\
(0.00738)\end{array}$ & \\
\hline Number of migrants in $\mathrm{HH}$ & & & $\begin{array}{c}0.0528 \\
(0.0416)\end{array}$ & $\begin{array}{c}0.0299 \\
(0.0395)\end{array}$ & \\
\hline Asset value of $\mathrm{HH}(\log )$ & & & $\begin{array}{l}0.0237 \\
(0.044)\end{array}$ & $\begin{array}{l}0.00667 \\
(0.0536)\end{array}$ & \\
\hline Land size of $\mathrm{HH}(\log )$ & & & $\begin{array}{c}0.007 \\
(0.00791)\end{array}$ & $\begin{array}{c}0.00876 \\
(0.012)\end{array}$ & \\
\hline HH head education (year) & & & $\begin{array}{c}0.018 \\
(0.0134)\end{array}$ & $\begin{array}{c}0.013 \\
(0.0137)\end{array}$ & \\
\hline 1 if $\mathrm{HH}$ had non-agricultural business & & & $\begin{array}{c}0.0524 \\
(0.0697)\end{array}$ & $\begin{array}{l}0.0441 \\
(0.104)\end{array}$ & \\
\hline 1 if $\mathrm{HH}$ was far from closest road & & & $\begin{array}{l}-0.0337 \\
(0.0656)\end{array}$ & $\begin{array}{l}-0.111 \\
(0.224)\end{array}$ & \\
\hline 1 if $\mathrm{HH}$ was far in altitude from village reference point & & & $\begin{array}{l}-0.149 * \\
(0.0732)\end{array}$ & $\begin{array}{l}-0.185 \\
(0.115)\end{array}$ & \\
\hline Observations & 490 & 490 & 441 & 441 & 441 \\
\hline $\begin{array}{l}\text { R-squared } \\
\text { Year dummy }\end{array}$ & 0.00141 & $\begin{array}{c}0.00779 \\
\text { Yes }\end{array}$ & 0.318 & 0.51 & 0.388 \\
\hline $\begin{array}{c}\text { Year } \times \text { district } \\
\text { Parish FE }\end{array}$ & & & Yes & $\begin{array}{l}\text { Yes } \\
\text { Yes }\end{array}$ & Yes \\
\hline Mother FE & & & & & Yes \\
\hline
\end{tabular}

(1) Standard errors are clustered at the district level. Significance level: ${ }^{*} p<0.1$. (2) In addition to the control variables listed, the regressions (3)-(5) control for a dummy indicating an area largely occupied by water surface, a dummy indicating that the distance from the household location to the reference point of the village was larger than the mean, a dummy indicating that the driving time to the nearest district town from the village was less than the mean, three dummies for the number of higher-level health facilities, and two dummies for the number of lower-level health facilities. (3) The placebo mobile money dummy takes a value of one in 2009 for the people who used mobile money in 2015; it takes a value of zero for the rest of the observations in the subset.

Table A6. Mobile money and remittances. Dependent variable: measures of remittances.

\begin{tabular}{ccc}
\hline & (1) & (2) \\
\hline VARIABLES & $\begin{array}{c}\mathbf{1} \text { if HH Received Remittances } \\
\text { in Past 12 Months }\end{array}$ & $\begin{array}{c}\text { Amount of Remittances } \\
\text { in Past 12 Months (log) }\end{array}$ \\
\hline 1 if HH used mobile money & $0.182^{* * *}$ & $0.727^{* * *}$ \\
Observations & $(0.04)$ & $(0.189)$ \\
R-squared & 1340 & 1339 \\
Year $\times$ district & 0.152 & 0.152 \\
Mother FE & Yes & Yes \\
& Yes & Yes
\end{tabular}

(1) Standard errors are clustered at the district level. Significance level: $* * * p<0.01$. (2) The regressions control for the years of education of the household head, the number of the household members, the number of migrants in the household, log of the value of the asset owned by the household, log of the size of the land used by the household, a dummy indicating that the household had a mobile phone, and a dummy indicating that the household had a non-agricultural business. (3) The mean value of the dummy indicating receipt of remittances in the past 12 months is 0.23 . 
Table A7. Regression using lagged mobile money indicator.

\begin{tabular}{|c|c|}
\hline \multicolumn{2}{|c|}{ Outcome Variable: 1 if Mother Received Recommended ANC (4 Times, 1-1-2). } \\
\hline & (1) \\
\hline \multicolumn{2}{|l|}{ VARIABLES } \\
\hline Lagged dummy of mobile money use & $\begin{array}{c}0.103 \\
(0.126)\end{array}$ \\
\hline Age (mother) & $\begin{array}{c}0.120) \\
(0.000298 \\
(0.0069)\end{array}$ \\
\hline Parity & $\begin{array}{c}0.132 * \\
(0.0651)\end{array}$ \\
\hline 1 if $\mathrm{HH}$ had mobile phone & $\begin{array}{c}-0.0411 \\
(0.111)\end{array}$ \\
\hline Number of HH members & $\begin{array}{c}0.0459^{* *} \\
(0.0175)\end{array}$ \\
\hline Number of migrants in $\mathrm{HH}$ & $\begin{array}{l}-0.0426 \\
(0.0406)\end{array}$ \\
\hline Asset value of $\mathrm{HH}(\log )$ & $\begin{array}{c}-0.0458 * \\
(0.0248)\end{array}$ \\
\hline Land size of $\mathrm{HH}(\log )$ & $\begin{array}{c}-0.0225 \text { * } \\
(0.0112)\end{array}$ \\
\hline HH head education (year) & $\begin{array}{c}0.0329 \\
(0.0257)\end{array}$ \\
\hline 1 if $\mathrm{HH}$ had non-agricultural business & $\begin{array}{c}0.102 \\
(0.0716)\end{array}$ \\
\hline Observations & 767 \\
\hline R-squared & 0.627 \\
\hline Year $\times$ district & Yes \\
\hline Mother FE & Yes \\
\hline
\end{tabular}

(1) Standard errors are clustered at the district level. Significance level: ${ }^{*} p<0.1,{ }^{* *} p<0.05$. (2) In addition to the control variables listed, the regression control for three dummies for the number of higher-level health facilities and two dummies for the number of lower-level health facilities. (3) The lagged dummy of mobile money use is constructed by changing the year of starting the use of mobile money one year later than the year originally reported by each household. For example, if a household reported that they started using mobile money in 2012, the lagged dummy of mobile money use takes a value of one for 2013-2015.

\section{References}

1. Mandira, S.; Jesim, P. Financial Inclusion and Development. J. Int. Dev. 2011, 628, 613-628.

2. Jack, W.; Suri, T. Risk Sharing and Transactions Costs: Evidence from Kenya's Mobile Money Revolution. Am. Econ. Rev. 2014, 104, 183-223. [CrossRef]

3. Riley, E. Mobile Money and Risk Sharing against Village Shocks. J. Dev. Econ. 2018, 135, 43-58. [CrossRef]

4. Munyegera, G.K.; Matsumoto, T. Mobile Money, Remittances, and Household Welfare: Panel Evidence from Rural Uganda. World Dev. 2016, 79, 127-137. [CrossRef]

5. Apiors, E.K.; Suzuki, A. Mobile Money, Individuals' Payments, Remittances, and Investments: Evidence from the Ashanti Region, Ghana. Sustainability 2018, 10. [CrossRef]

6. Lee, J.N.; Morduch, J.; Ravindran, S.; Shonchoy, A.; Zaman, H. Poverty and Migration in the Digital Age: Experimental Evidence on Mobile Banking in Bangladesh. Am. Econ. J. Appl. Econ. 2020, in press.

7. Munyegera, G.K.; Matsumoto, T. ICT for Financial Access: Mobile Money and the Financial Behavior of Rural Households in Uganda. Rev. Dev. Econ. 2017, 1-22. [CrossRef]

8. Tabetando, R. Essays on The Impact of Mobile Money on Human Capital and Agricultural Investment: Evidence from Rural Uganda (Doctoral Dissertation). Available online: https://grips.repo.nii.ac.jp/?action= repository_action_common_download\&item_id=1595\&item_no=1\&attribute_id=25\&file_no=3 (accessed on 18 March 2020).

9. Dupas, P. Health Behavior in Developing Countries. Annu. Rev. Econ. 2011, 3, 425-449. [CrossRef]

10. Dupas, P.; Robinson, J. Why Don't the Poor Save More? Evidence from Health Savings Experiments. Am. Econ. Rev. 2013, 103, 1138-1171. [CrossRef] 
11. Tarozzi, B.A.; Mahajan, A.; Blackburn, B.; Kopf, D.; Krishnan, L.; Yoong, J. Micro-Loans, Insecticide-Treated Bednets, and Malaria: Evidence from a Randomized Controlled Trial. Am. Econ. Rev. 2014, 104, 1909-1941. [CrossRef]

12. Ensor, T.; Cooper, S. Overcoming Barriers to Health Service Access: Influencing the Demand Side. Health Policy Plan. 2004, 19, 69-79. [CrossRef] [PubMed]

13. Barros, A.J.; Ronsmans, C.; Axelson, H.; Loaiza, E.; Bertoldi, A.D.; Frana, G.V.; Bryce, J.; Boerma, J.T.; Victora, C.G. Equity in Maternal, Newborn, and Child Health Interventions in Countdown to 2015: A Retrospective Review of Survey Data from 54 Countries. Lancet 2012, 379, 1225-1233. [CrossRef]

14. Schmidt, J.-O.; Ensor, T.; Hossain, A.; Khan, S. Vouchers as Demand Side Financing Instruments for Health Care: A Review of the Bangladesh Maternal Voucher Scheme. Health Policy (N. Y.) 2010, 96, 98-107. [CrossRef] [PubMed]

15. Powell-Jackson, T.; Hanson, K. Financial Incentives for Maternal Health: Impact of a National Programme in Nepal. J. Health Econ. 2012, 31, 271-284. [CrossRef]

16. Grépin, K.A.; Habyarimana, J.; Jack, W. Cash on Delivery: Results of a Randomized Experiment to Promote Maternal Health Care in Kenya. J. Health Econ. 2019, 65, 15-30. [CrossRef]

17. WHO; UNICEF; UNFPA; The World Bank; The United Nations Population Devision. Trends in Maternal Mortality: 1990 to 2013. Available online: http://apps.who.int/iris/bitstream/10665/112682/2/9789241507226_ eng.pdf (accessed on 11 July 2019).

18. Uganda Bureau of Statistics (UBOS) and ICF International Inc. Uganda Demographic and Health Survey. 2011. Available online: https://dhsprogram.com/pubs/pdf/FR264/FR264.pdf (accessed on 11 July 2019).

19. Halim, N.; Bohara, A.K.; Ruan, X. Healthy Mothers, Healthy Children: Does Maternal Demand for Antenatal Care Matter for Child Health in Nepal? Health Policy Plan. 2011, 26, 242-256. [CrossRef]

20. WHO. Managing Complications in Pregnancy and Childbirth: A Guide for Midwives and Doctors. Available online: http://apps.who.int/iris/bitstream/10665/43972/1/9241545879_eng.pdf (accessed on 11 July 2019).

21. Manang, F.; Yamauchi, C. The Impact of Access to Health Facilities on Maternal Care Use, Travel Patterns and Health Status: Evidence from Longitudinal Data from Uganda. Econ. Dev. Cult. Chang. 2019. [CrossRef]

22. Singh, A.; Kumar, K.; McDougal, L.; Silverman, J.G.; Atmavilas, Y.; Gupta, R.; Raj, A. Does Owning a Bank Account Improve Reproductive and Maternal Health Services Utilization and Behavior in India? Evidence from the National Family Health Survey 2015-16. SSM Popul. Health 2019, 7, 100396. [CrossRef]

23. Orton, L.; Pennington, A.; Nayak, S.; Sowden, A.; White, M.; Whitehead, M. Group-Based Microfinance for Collective Empowerment: A Systematic Review of Health Impacts. Bull. World Health Organ. 2016, 94, 694-704A. [CrossRef]

24. Bersudskaya, V.; McCaffrey, M. AGENTS COUNT. Available online: http://www.helix-institute.com/sites/ default/files/Publications/AgentsCount_0.pdf (accessed on 16 March 2020).

25. Bank of Uganda. Annual Supervision Report. Available online: https://www.bou.or.ug/bou/bouwebsite/ bouwebsitecontent/Supervision/Annual_Supervision_Report/asr/Annual-Supervision-Report-December2015.pdf (accessed on 16 March 2020).

26. TeleGeography. Almost 20 Million Mobile Money Users in Uganda. Available online: https://www. commsupdate.com/articles/2015/12/17/almost-20-million-mobile-money-users-in-uganda/ (accessed on 16 March 2020).

27. Lawn, J.E.; Ssengooba, F.; Kerber, K.; Matovu, F.; Goodman, C.; Lynch, C.A.; Haemmerli, M.; Fernandez, Y.; Waiswa, P.; Macleod, D.; et al. Two Decades of Antenatal and Delivery Care in Uganda: A Cross-Sectional Study Using Demographic and Health Surveys. BMC Health Serv. Res. 2018, 18, 1-15. [CrossRef]

28. Ministry of Health. Uganda Clinical Guidelines. 2016. Available online: https://www.health.go.ug/sites/ default/files/UgandaClinicalGuidelines2016_FINAL.pdf (accessed on 10 July 2019).

29. Uganda Bureau of Statistics (UBOS) and ICF. Uganda Demographic and Health Survey. 2016. Available online: https://dhsprogram.com/pubs/pdf/FR333/FR333.pdf (accessed on 28 October 2019).

30. Ministry of Health. Health Facilities Inventory. July 2012. Available online: http://library.health. go.ug/publications/health-infrastructure-physical-infrastructure/health-facility-inventory (accessed on 15 October 2019).

31. Gabrysch, S.; Campbell, O.M.R. Still Too Far to Walk: Literature Review of the Determinants of Delivery Service Use. BMC Pregnancy Childbirth 2009, 9, 34. [CrossRef] [PubMed] 
32. Bank of Uganda. Annual Report. Available online: https://www.bou.or.ug/bou/bouwebsite/FinancialStability/ AnnualReport/Annual/index.html (accessed on 18 March 2020).

33. Sacks, E.; Vail, D.; Austin-Evelyn, K.; Greeson, D.; Atuyambe, L.M.; MacWan'Gi, M.; Kruk, M.E.; Grépin, K.A. Factors Influencing Modes of Transport and Travel Time for Obstetric Care: A Mixed Methods Study in Zambia and Uganda. Health Policy Plan. 2016, 31, 293-301. [CrossRef] [PubMed]

34. Jehan, K.; Sidney, K.; Smith, H.; Costa, D. Improving Access to Maternity Services: An Overview of Cash Transfer and Voucher Schemes in South Asia. Reprod. Health Matters 2012, 20, 142-154. [CrossRef]

35. Bellows, B.; Kyobutungi, C.; Mutua, M.K.; Warren, C.; Ezeh, A. Increase in Facility-Based Deliveries Associated with a Maternal Health Voucher Programme in Informal Settlements in Nairobi, Kenya. Health Policy Plan. 2013, 28, 134-142. [CrossRef] [PubMed]

36. Tabetando, R.; Matsumoto, T. Mobile Money, Risk Sharing, and Educational Investment: Panel Evidence from Rural Uganda. Rev. Dev. Econ. 2020, 24, 84-105. [CrossRef]

37. Lamichhane, P.; Sharma, A.; Mahal, A. Impact Evaluation of Free Delivery Care on Maternal Health Service Utilisation and Neonatal Health in Nepal. Health Policy Plan. 2017, 32, 1427-1436. [CrossRef]

38. McKinnon, B.; Harper, S.; Kaufman, J.S.; Bergevin, Y. Removing User Fees for Facility-Based Delivery Services: A Difference-in-Differences Evaluation from Ten Sub-Saharan African Countries. Health Policy Plan. 2015, 30, 432-441. [CrossRef]

39. Allendorf, K. The Quality of Family Relationships and Use of Maternal Health-Care Services in India. Stud. Fam. Plann. 2010, 41, 263-276. [CrossRef]

40. Beckett, M.; Da Vanzo, J.; Sastry, N.; Panis, C.; Peterson, C. The Quality of Retrospective Data: An Examination of Long-Term Recall in a Developing Country. J. Hum. Resour. 2001, 36, 593-625. [CrossRef]

41. Gertler, P.; Martinez, S.; Premand, P.; Rawlings, L.B.; Vermeersch, C.M. Impact Evaluation in Practice; World Bank: Washington, DC, USA, 2016.

42. Angrist, J.D.; Pischke, J.-S. Mastering Metrics; Princeton University Press: Princeton, NJ, USA, 2015.

43. Lotto, J. Examination of the Status of Financial Inclusion and Its Determinants in Tanzania. Sustainability 2018, 10. [CrossRef]

44. Bellemare, M.F.; Masaki, T.; Pepinsky, T.B. Lagged Explanatory Variables and the Estimation of Causal Effect. J. Polit. 2017, 79, 949-963. [CrossRef]

45. Hunter, B.M.; Harrison, S.; Portela, A.; Bick, D. The Effects of Cash Transfers and Vouchers on the Use and Quality of Maternity Care Services: A Systematic Review. PLoS ONE 2017, 12, e0173068. [CrossRef] [PubMed]

46. Ahmed, H.; Cowan, B.W. Mobile Money and Healthcare Use: Evidence From East Africa. Nber Working Paper Series. Available online: http://www.nber.org/papers/w25669 (accessed on 15 October 2019). 